\title{
On the absolute calibration of $\mathrm{SO}_{2}$ cameras
}

\author{
P. Lübcke ${ }^{1,2}$, N. Bobrowski ${ }^{1}$, S. Illing ${ }^{1}$, C. Kern ${ }^{3}$, J. M. Alvarez Nieves ${ }^{4}$, L. Vogel ${ }^{1}$, J. Zielcke ${ }^{1}$, H. Delgado Granados ${ }^{4}$, \\ and U. Platt ${ }^{1}$ \\ ${ }^{1}$ Institut für Umweltphysik, Im Neuenheimer Feld 229, 69120 Heidelberg, Germany \\ ${ }^{2}$ Max-Planck-Institut für Chemie, Mainz, Germany \\ ${ }^{3}$ Cascades Volcano Observatory, US Geological Survey, Vancouver, WA, USA \\ ${ }^{4}$ Departamento de Vulcanologica, Instituto de Geofísica, Universidad Nacional Autónoma de México, México D. F., Mexico \\ Correspondence to: P. Lübcke (pluebcke@iup.uni-heidelberg.de)
}

Received: 13 July 2012 - Published in Atmos. Meas. Tech. Discuss.: 3 September 2012

Revised: 5 February 2013 - Accepted: 11 February 2013 - Published: 14 March 2013

\begin{abstract}
Sulphur dioxide emission rate measurements are an important tool for volcanic monitoring and eruption risk assessment. The $\mathrm{SO}_{2}$ camera technique remotely measures volcanic emissions by analysing the ultraviolet absorption of $\mathrm{SO}_{2}$ in a narrow spectral window between 300 and $320 \mathrm{~nm}$ using solar radiation scattered in the atmosphere. The $\mathrm{SO}_{2}$ absorption is selectively detected by mounting band-pass interference filters in front of a two-dimensional, UV-sensitive $\mathrm{CCD}$ detector. One important step for correct $\mathrm{SO}_{2}$ emission rate measurements that can be compared with other measurement techniques is a correct calibration. This requires conversion from the measured optical density to the desired $\mathrm{SO}_{2}$ column density (CD). The conversion factor is most commonly determined by inserting quartz cells (cuvettes) with known amounts of $\mathrm{SO}_{2}$ into the light path. Another calibration method uses an additional narrow field-of-view Differential Optical Absorption Spectroscopy system (NFOVDOAS), which measures the column density simultaneously in a small area of the camera's field-of-view. This procedure combines the very good spatial and temporal resolution of the $\mathrm{SO}_{2}$ camera technique with the more accurate column densities obtainable from DOAS measurements.

This work investigates the uncertainty of results gained through the two commonly used, but quite different, calibration methods (DOAS and calibration cells). Measurements with three different instruments, an $\mathrm{SO}_{2}$ camera, a NFOVDOAS system and an Imaging DOAS (I-DOAS), are presented. We compare the calibration-cell approach with the calibration from the NFOV-DOAS system. The respective results are compared with measurements from an I-DOAS
\end{abstract}

to verify the calibration curve over the spatial extent of the image.

The results show that calibration cells, while working fine in some cases, can lead to an overestimation of the $\mathrm{SO}_{2}$ $\mathrm{CD}$ by up to $60 \%$ compared with CDs from the DOAS measurements. Besides these errors of calibration, radiative transfer effects (e.g. light dilution, multiple scattering) can significantly influence the results of both instrument types. The measurements presented in this work were taken at Popocatépetl, Mexico, between 1 March 2011 and 4 March 2011. Average $\mathrm{SO}_{2}$ emission rates between 4.00 and $14.34 \mathrm{~kg} \mathrm{~s}^{-1}$ were observed.

\section{Introduction}

$\mathrm{SO}_{2}$ emission rates have long been routinely monitored at a considerable number of volcanoes for volcanic risk assessment. More recently, permanent Differential Optical Absorption Spectroscopy (DOAS, Platt and Stutz, 2008) systems were installed at a number of volcanoes in order to improve the temporal resolution of the datasets - largely by the Network for Observation of Volcanic and Atmospheric Change (NOVAC, Galle et al., 2010). The chemical lifetime of $\mathrm{SO}_{2}$ in the atmosphere (typically several days) is long compared to plume ages (minutes to hours) typically observed by groundbased remote sensing measurements (e.g. Oppenheimer et al., 1998; von Glasow et al., 2009). Moreover, its low background concentration in the atmosphere makes volcanic $\mathrm{SO}_{2}$ easy to identify by remote sensing techniques. Since the correlation spectrometer (COSPEC) was first used in the 1970s 
(e.g. Moffat and Millan, 1971; Stoiber et al., 1983), the remote sensing of volcanic gases has evolved and DOAS currently is, together with the continuing use of COSPEC, the most frequently applied technique. In addition to small instrument size and thus easy portability, DOAS can be used to identify various trace gases simultaneously by their distinguishable differential absorption features. $\mathrm{SO}_{2}$ is analysed in this work but $\mathrm{NO}_{2}, \mathrm{BrO}$ or $\mathrm{O}_{3}$ can, for instance, be measured as well.

DOAS is applied at volcanoes in various implementations. One commonly used method involves scanning DOAS systems that measure in a narrow field-of-view (NFOV) and perform scans through a cross-section of the volcanic plume by moving the telescope and recording spectra at different elevation angles. A drawback of scanning DOAS systems is that it may take several minutes to complete a scan through the cross-section of a volcanic plume. Other instruments use UV spectrometers with a wide field-of-view (FOV) telescope (i.e. two spectrometers equipped with optical systems that capture light from an entire plume cross-section at once) to obtain emission rate measurements with a higher temporal resolution (McGonigle et al., 2009; Boichu et al., 2010).

The Imaging DOAS (I-DOAS) is an instrument that allows the spectroscopic measurement of two-dimensional trace gas distributions (Lohberger et al., 2004; Bobrowski et al., 2006; Louban et al., 2009). Typical I-DOAS instruments, such as the one used during this study, take approximately $20 \mathrm{~min}$ to acquire a two-dimensional image of the trace gas distribution. During this time it produces an image that has a horizontal FOV comparable to our $\mathrm{SO}_{2}$ camera (the camera has a FOV of $22.4^{\circ}$ ).

The DOAS technique has important advantages: besides the ability to resolve different species in a single measurement, it offers the possibility to treat radiative transfer issues (e.g. multiple scattering inside the volcanic plume or the light dilution effect, i.e. radiation scattered into the light path between the volcanic plume and instrument without penetrating the volcanic plume) through the availability of spectral information (Kern et al., 2010a). Nevertheless, all DOAS measurement geometries require compromising on either spatial or time resolution.

In contrast to standard DOAS measurements, the $\mathrm{SO}_{2}$ camera can measure two-dimensional $\mathrm{SO}_{2} \mathrm{CD}$ (column density) distributions with a high spatial resolution and a high frequency on the order of $1 \mathrm{~Hz}$, but with extremely reduced spectral information. The measurement principle employs one or two interference filters and a UV-sensitive CCD. One filter (Filter A) measures the optical density of $\mathrm{SO}_{2}$; a second filter (Filter B) is used to correct for aerosol scattering and radiative transfer effects (Mori and Burton, 2006; Dalton et al., 2009; Kantzas et al., 2010; Kern et al., 2010a). Because aerosol scattering on particles with diameters of the order of the radiation wavelength actually does exhibit a slight wavelength dependency, the second filter cannot completely remove the influence of aerosol and plume condensation on the measurement results.

While $\mathrm{SO}_{2}$ cameras are certainly limited by the fact that only one trace gas can be measured and that radiative transfer effects can potentially lead to an inaccurate calibration, the $\mathrm{SO}_{2}$ camera can nevertheless be an important tool for measuring $\mathrm{SO}_{2}$ emission rates under certain conditions, in particular for measuring the total $\mathrm{SO}_{2}$ emitted during an event (Mori and Burton, 2009) or when the wind speed is spatially variable. The high time resolution of the $\mathrm{SO}_{2}$ camera allows the observation of dynamic effects in the volcanic plume and therefore can be used to obtain $\mathrm{SO}_{2}$ emission rates at time resolutions on the order of a second. In fact, it was recently shown that optical flow models can be applied to derive 2-D plume velocity fields (see Kern et al., 2012a). Further advantages of high time resolution $\mathrm{SO}_{2}$ emission rate data lie in the synergetic use of several geophysical methods which in combination will allow better interpretation of the volcanic activity signals (e.g. Dalton et al., 2010; Nadeau et al., 2011). For a better integration of various data sets, it is important that they have a comparable time resolution. In particular, the $\mathrm{SO}_{2}$ camera's time resolution of $1 \mathrm{~s}$ is ideal for the integration of seismic and gas emission data.

The $\mathrm{SO}_{2}$ camera measures the optical density of $\mathrm{SO}_{2}$. For the calculation of $\mathrm{SO}_{2}$ emission rates the first crucial step is to calibrate the $\mathrm{SO}_{2}$ camera: the optical densities have to be converted to $\mathrm{SO}_{2} \mathrm{CDs}$, i.e. the number density of $\mathrm{SO}_{2}$ integrated over the light path (e.g. Mori and Burton, 2006; Bluth et al., 2007; Kern et al., 2010b). This calibration is mostly performed with calibration cells (Mori and Burton, 2006; Bluth et al., 2007; Dalton et al., 2009; Kantzas et al., 2010), but can also be performed by taking simultaneous measurements with a DOAS system. Errors made during the conversion directly influence the obtained $\mathrm{SO}_{2} \mathrm{CD}$ and therefore propagate into all quantities derived from the $\mathrm{SO}_{2} \mathrm{CD}$, such as the $\mathrm{SO}_{2}$ emission rate, the total $\mathrm{SO}_{2}$ emitted during an event, or the mass of magma responsible for the degassing process. Misleading conclusions may easily be drawn from such data sets and can lead to incorrect conclusions about the volcanic system.

While the DOAS calibration appears preferable, as it can detect ash and aerosol influences, it has not been studied adequately yet. In this paper we present results from a measurement campaign at Popocatépetl volcano (Mexico) in March 2011. We compare calibration curves obtained from DOAS measurements with those obtained from the calibration cells and determine the magnitude of error for the calibration-cell method that we observed during our measurements.

\section{The measurement principle of the $\mathrm{SO}_{2}$ camera}

When scattered solar radiation passes through a volcanic plume, it is scattered and absorbed by gases, ash and aerosol 
in the plume. The $\mathrm{SO}_{2}$ camera measures the optical density of $\mathrm{SO}_{2}$ by applying one or two band-pass filters (Mori and Burton, 2006; Bluth et al., 2007). Filter A transmits radiation in a region where $\mathrm{SO}_{2}$ absorption is prominent and sufficient solar radiation intensity is available to allow reasonable exposure times. ${ }^{1}$ This is the case for the wavelength region between 300 and $320 \mathrm{~nm}$. The measured intensity $I_{\mathrm{A}, \mathrm{M}}$ is influenced by $\mathrm{SO}_{2}$ absorption, but also by aerosols, ash and plume condensation. The optical density $\tau_{\mathrm{A}}$ for Filter A can be written as the following:

$\tau_{\mathrm{A}}=-\ln \frac{I_{\mathrm{A}, \mathrm{M}}}{I_{\mathrm{A}, 0}}$,

with incident spectral radiation intensity $I_{\mathrm{A}, 0}$ and radiation intensity $I_{\mathrm{A}, \mathrm{M}}$ after passing through the volcanic plume.

A first order correction can be performed with a second filter that transmits radiation in a region where $\mathrm{SO}_{2}$ absorption is negligible, but the influence of the other effects is comparable ( 325 to $335 \mathrm{~nm}$ ). This correction is based on the assumption that these effects are spectrally flat between 300 and $335 \mathrm{~nm}$.

The optical density $\tau_{\mathrm{B}}$ for Filter $\mathrm{B}$, which is not influenced by $\mathrm{SO}_{2}$ absorption, is given by

$$
\tau_{\mathrm{B}}=-\ln \frac{I_{\mathrm{B}, \mathrm{M}}}{I_{\mathrm{B}, 0}}
$$

$\tau$ is the difference between the optical densities for Filter A and Filter B; it is also referred to as the apparent absorbance (AA):

$$
\begin{aligned}
\tau=\mathrm{AA} & =\tau_{\mathrm{A}}-\tau_{\mathrm{B}}=-\ln \frac{I_{\mathrm{A}, \mathrm{M}}}{I_{\mathrm{A}, 0}}+\ln \frac{I_{\mathrm{B}, \mathrm{M}}}{I_{\mathrm{B}, 0}} \\
& =\ln \frac{\frac{I_{\mathrm{B}, \mathrm{M}}}{I_{\mathrm{B}, 0}}}{\frac{I_{\mathrm{A}, \mathrm{M}}}{I_{\mathrm{A}, 0}}}=\ln \frac{I_{\mathrm{B}, \mathrm{M}}}{I_{\mathrm{A}, \mathrm{M}}} \cdot \frac{I_{\mathrm{A}, 0}}{I_{\mathrm{B}, 0}} .
\end{aligned}
$$

Since the AA cannot directly be used to calculate the $\mathrm{SO}_{2}$ emission rate, a calibration has to be performed to convert AA values to $\mathrm{SO}_{2} \mathrm{CDs}$.

\footnotetext{
${ }^{1}$ The choice of a reasonable exposure time is mainly influenced by two effects: On the one hand, the volcanic plume moves between two exposures. With our set-up and measurement geometry (Table 2), the distance between two pixels is approximately $2.5 \mathrm{~m}$. Assuming a wind-speed of $10 \mathrm{~m} \mathrm{~s}^{-1}$, this leads to a total exposure time of $0.25 \mathrm{~s}$ if plume features should not move more than one pixel between subsequent images. On the other hand, the exposure time should be long compared to the shutter opening time. If the exposure time is of similar magnitude as the shutter opening time, this can lead to less exposure of, e.g. the corners of the image (vignetting). This effect can lead to artefacts in the image when different exposure times are used for background and measurement images.
}

\section{Instruments applied during the measurements at Popocatépetl, Mexico}

An $\mathrm{SO}_{2}$ camera system with an integrated NFOV-DOAS system was designed and built at the University of Heidelberg laboratory, Germany. Field measurements were conducted at Popocatépetl, Mexico, together with an I-DOAS instrument, which was also custom-built in the University of Heidelberg laboratory. All three instruments $\left(\mathrm{SO}_{2}\right.$ camera, NFOVDOAS and I-DOAS) will be briefly described in this section. More detailed information about the I-DOAS can be found in Louban et al. (2009).

\subsection{Design and instrumental set-up of the $\mathrm{SO}_{2}$ camera}

The central element of the $\mathrm{SO}_{2}$ camera used in this study is an Apogee Instruments Alta U6 CCD array which serves as a detector. The array consists of $1024 \times 1024$ pixels with a pixel size of $24 \times 24 \mu \mathrm{m}$, resulting in a large detector area of $24.58 \times 24.58 \mathrm{~mm}$. Short exposure times (approximately $0.2-0.4 \mathrm{~s}$ ) can therefore be achieved despite the fact that the detector quantum efficiency $Q$ and the scattered radiation intensity are low in the UV regions used in the measurements. The optical set-up (see Fig. 2) consisted of a single $31.5 \mathrm{~mm}$ diameter plano convex fused silica lens with a focal length of $f=60 \mathrm{~mm}$ and two band-pass interference filters mounted in a filter wheel between the lens and the detector. This set-up was chosen to reduce influences from a variable filter illumination angle (see Kern et al., 2010b, for more detailed information about this effect). An iris aperture was installed directly in front of the lens. Aperture settings were only adjusted at the beginning of the measurement campaign, as changes in the aperture influence the calibration (see Sect. 4.3). While conducting the measurements presented here, an aperture of roughly $f / 8$ was used.

Two interference filters from Eureca Messtechnik with a central transmittance wavelength of $315 \mathrm{~nm}$ (Filter A, FWHM $10 \mathrm{~nm}$ ), and $330 \mathrm{~nm}$ (Filter B, FWHM $10 \mathrm{~nm}$ ), were used for the measurements. The filters are installed in a custom-made filter wheel that consists of an aluminium mount, which holds the two filters, and a standard servo unit (as, e.g. used in model airplanes), which is operated by a Phidgets ${ }^{\circledR}$ USB servo controller (PhidgetAdvancedServo 8-Motor). The Phidget ${ }^{\complement}$ controller also controls two further servo motors. These servo motors can each insert one of two calibration cells containing known $\mathrm{SO}_{2}$ concentrations in front of the aperture, each covering the entire FOV of the camera. The calibration cells were filled with $\mathrm{SO}_{2}$ concentrations corresponding to column densities of $3.5 \times 10^{17} \mathrm{molec} \mathrm{cm}^{-2}\left(140 \mathrm{ppmm}^{2}\right)$ and $1.8 \times 10^{18} \mathrm{molec}^{-2}(720 \mathrm{ppmm})$, respectively. The

\footnotetext{
${ }^{2}$ We use the unit of ppmm similar to Kern et al. (2010a). The units molecules $\mathrm{cm}^{-2}$ where converted to ppmm assuming standard pressure and a temperature of $20^{\circ} \mathrm{C}$ throughout the text: $1 \mathrm{ppmm}=2.5 \times 10^{15}$ molecules $\mathrm{cm}^{-2}$.
} 


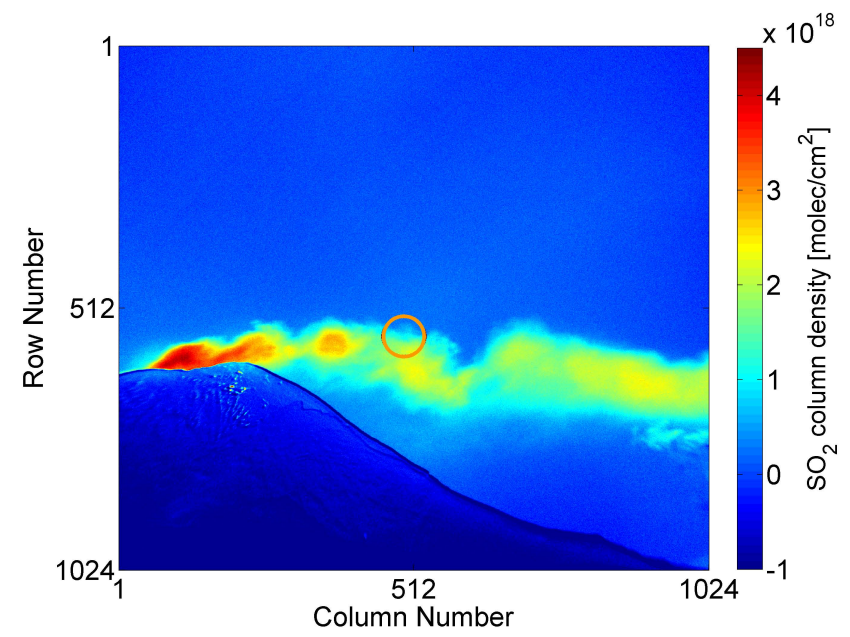

Fig. 1. $\mathrm{SO}_{2}$ camera image from Popocatépetl acquired from Paso de Cortes on the 1 March 2011, the orange circle shows the fieldof-view of the telescope of the NFOV-DOAS instrument used for calibration (see text).

calibration cells can be moved into the light path separately or both at the same time, thus giving three measurement points for calibration. More calibration cells would improve the quality of the calibration curve but also drastically increase the mechanical complexity of the camera.

\subsection{The Narrow Field-of-View DOAS}

For calibration purposes a narrow field-of-view DOAS (NFOV-DOAS) system was installed inside the camera housing. It measures the $\mathrm{SO}_{2} \mathrm{CD}$ at the approximate centre of the camera image (see Fig. 1 and Kern et al., 2010b). The DOAS system consists of an Ocean Optics USB2000+ spectrometer, a $400 \mu \mathrm{m}$ fibre, a Hoya U330 filter to reduce stray light, and a telescope with a quartz lens with a focal length of $f=30 \mathrm{~mm}$ and a diameter of $18.5 \mathrm{~mm}$. The telescope of the DOAS system is mechanically attached to the camera optics to minimize changes in the FOV relative to the camera images. The spectrometer temperature was stabilized to $15^{\circ} \mathrm{C}$ for all measurements presented. This was done with a peltier element controlled by an Arduino board (Arduino Uno manufactured by SmartProjects) running PID controller software and an Analog Devices ADT7410 temperature sensor. The spatial resolution, FOV and the exposure times used during the measurements are summarized in Table 1.

\subsection{The Imaging DOAS instrument}

The Imaging DOAS (I-DOAS) is an instrument that uses a two-dimensional CCD as a detector in an imaging spectrometer to measure two-dimensional trace gas CDs (Lohberger et al., 2004; Bobrowski et al., 2006; Louban et al., 2009). Note that the I-DOAS instrument determines the two-dimensional distribution of the $\mathrm{SO}_{2} \mathrm{CD}$ - just as the $\mathrm{SO}_{2}$ camera -
Table 1. Optical parameters and settings of the instruments used during the measurements.

\begin{tabular}{ll}
\hline I-DOAS & \\
\hline Co-added exposures per spectrum & 10 \\
Exposure time & $0.5-2.5 \mathrm{~s}$ \\
Resolution (pixel $h \times v)$ & $175 \times 255$ \\
Solid angle per pixel & $0.26^{\circ} \times 0.05^{\circ}$ \\
FOV per column & $0.26^{\circ} \times 13.1^{\circ}$ \\
Scanned solid angle & $45.5^{\circ} \times 13.1^{\circ}$ \\
\hline $\mathrm{SO}_{2}$-camera & \\
\hline Exp. time Filter A & $0.25-1 \mathrm{~s}$ \\
Exp. time Filter B & $0.1-0.3 \mathrm{~s}$ \\
Resolution (pixel $h \times v)$ & $1024 \times 1024$ \\
Solid angle per pixel & $0.02^{\circ} \times 0.02^{\circ}$ \\
FOV & $22.4^{\circ} \times 22.4^{\circ}$ \\
\hline NFOV-DOAS & \\
\hline Co-added exposures per spectrum & 15 \\
Exposure Time & $0.3-0.6 \mathrm{~s}$ \\
FOV & $2.5^{\circ}$ \\
\hline
\end{tabular}

however, using the DOAS technique rather than Eq. (3). During the measurements, the horizontal direction of the CCD was used to resolve spectral information, while the vertical direction was used to capture one spatial dimension. The second spatial dimension (horizontal direction) is obtained by applying the push-broom method, realized by rotating a mirror to scan along the second spatial dimension. The I-DOAS instrument uses a quartz lens with $f=30 \mathrm{~mm}(d=20 \mathrm{~mm})$ to image the incident radiation onto the entrance slit of the spectrograph (Jobin Yvon UFS-200, $f=21 \mathrm{~cm}, f / \#=3.2$, grating: 1200 lines $\mathrm{mm}^{-1}$ ); an Andor DV-420-OE (1024 pixel columns by 255 pixel rows) serves as a detector. Measurements were conducted simultaneous to the $\mathrm{SO}_{2}$ camera observations on 4 March 2011 to compare the NFOV-DOAS calibration with a second instrument and to verify the calibration over the spatial extent of the image instead of only the small region captured by the NFOV-DOAS. Information about the spatial resolution, FOV and settings are shown in Table 1.

\section{Calibrating the $\mathrm{SO}_{2}$ camera}

A calibration has to be performed to convert AA values to $\mathrm{SO}_{2}$ column densities. The camera calibration depends on the incoming solar radiation (i.e. the solar zenith angle, solar azimuth angle, and most importantly, changes in strength of stratospheric $\mathrm{O}_{3}$ absorptions); therefore the calibration typically has to be performed several times per day. Kantzas et al. (2010) found the calibration to be constant on the order of an hour during daytime, and more variable near sunrise or 
sunset. The camera calibration can be performed in several ways:

1. Calibrating with $\mathrm{SO}_{2}$ filled calibration cells, which are placed in front of the camera. This is probably the most commonly used method today (e.g. Mori and Burton, 2006; Dalton et al., 2009; Kantzas et al., 2010).

2. DOAS measurements are used for first-order corrections of in-plume ash and aerosols (Holland et al., 2011) but can also solely be used to calibrate the camera. A DOAS instrument that measures in a small area of the camera image (see Fig. 1) produces $\mathrm{SO}_{2} \mathrm{CD} / \mathrm{AA}$ pairs from which a calibration curve can be derived. A measurement set-up of an $\mathrm{SO}_{2}$ camera with a co-aligned DOAS system can combine the strengths of both techniques and result in accurate $\mathrm{SO}_{2}$ emission rate measurements with a high spatial and temporal resolution.

3. Simultaneous I-DOAS measurements (e.g. Louban et al., 2009) can be used for calibration as well. However, the instrumental set-up is complicated and measurements are slow.

The calibration with quartz cells will be referred to as cell calibration (see Sect. 4.1); calibration from DOAS measurements will be referred to as DOAS calibration (see Sect. 4.2).

\subsection{The calibration cell method}

In practice, camera calibration with cells can be performed in several ways; the simplest approach is to manually place calibration cells in front of the camera. Automated insertion of the cells is also possible, as in our case (see Sect. 3.1), but this increases the complexity of the instrument.

When taking images through a calibration cell with known $\mathrm{SO}_{2} \mathrm{CD}$ that covers the camera's entire FOV, the cell and background images through each filter can be used to derive an AA value (see Eq. 3) for each image pixel. Thus, a calibration curve can be obtained from AA/CD pairs derived from several measurements with calibration cells containing different $\mathrm{SO}_{2}$ concentrations.

Another method is using several calibration cells (with different column densities) that are attached to a mount and are distributed within the FOV of the camera, with each cell covering a (small) area within the FOV (Dalton et al., 2009). While several calibration cells in a single image reduce the time needed for calibration image acquisition, there are disadvantages. If the camera's response to a given $\mathrm{SO}_{2}$ column varies at different positions within the image and the calibration cells are not placed in the same position for all measurements, the calibration curve will become unreliable. The variation of response to a given $\mathrm{SO}_{2} \mathrm{CD}$ is caused by variations of the transmission curves of the interference filters with changing illumination angle (see Kern et al., 2010b, and Sect. 4.3).
Moreover, for both methods mentioned above, rays entering the camera through the calibration cell traverse the cell at different angles and thus travel different distances through the cell. This leads to somewhat different $\mathrm{SO}_{2}$ column densities in different parts of the image, though this issue can be corrected for by applying geometrical considerations (i.e. calculating the length of the light path through the cell for different illumination angles).

A calibration curve obtained this way only shows the camera's reaction to pure $\mathrm{SO}_{2}$. Additionally, it can usually not be performed with the same viewing direction as the plume measurements and needs to be repeated throughout the day to assess changes in the incoming solar radiation.

\subsection{The DOAS calibration method}

As mentioned above, a DOAS system that has a FOV matching a small area of the camera image can be used for calibration (Kern et al., 2010b). If the plume passes the FOV of the telescope, the spectrometer measures several $\mathrm{SO}_{2} \mathrm{CD}$ values while the camera measures the corresponding AA values. From these values, a calibration curve from data measured directly in the volcanic plume can be obtained. With this method changes of the calibration that result from changing incoming solar radiation or from condensation and aerosols in the volcanic plume can be identified. The spectroscopic data from the DOAS instrument can also be used for more sophisticated radiative transfer corrections (Kern et al., 2010a). Radiative transfer effects, such as the light dilution effect or multiple scattering inside the volcanic plume, can lead to large errors. Underestimation or overestimation of the true $\mathrm{CD}$ are both possible.

For an exact calibration, two further conditions have to be fulfilled:

1. The DOAS calibration should cover the entire range of appearing $\mathrm{SO}_{2}$ column densities. Care has to be taken that, over time, the DOAS telescope actually sees the whole range of $\mathrm{SO}_{2} \mathrm{CDs}$ that occur in the image. This may sometimes require changing the position of the DOAS FOV within the camera image or adjusting the orientation of the entire $\mathrm{SO}_{2}$ camera-DOAS set-up.

2. The calibration from the DOAS is only valid in the small area where the FOVs of both instruments coincide. Typically this is at - or close to - the centre of the camera image. For the remaining pixels of the image, the sensitivity has to be assumed to vary in the same way or has to be characterised, e.g. by taking images with several calibration cells covering the complete FOV (see Sect. 4.3). However, if characterised carefully (e.g. in the laboratory), the DOAS calibration method can eliminate the need to perform calibration cell measurements in the field. 


\subsection{Non-uniformity of calibration across the field of view}

Typically, $\mathrm{SO}_{2}$ cameras show an increase in sensitivity toward a given $\mathrm{SO}_{2} \mathrm{CD}$ with increasing distance from the optical axis (i.e. the sensitivity increases towards the corners of the image). The AA for a given $\mathrm{SO}_{2} \mathrm{CD}$ is influenced by the transmission curve of band-pass interference filters (Kern et al., 2010b). Interference filters show a shift of the filter transmission window towards shorter wavelengths when not illuminated perpendicularly. Since the $\mathrm{SO}_{2}$ absorption cross-section becomes larger towards shorter wavelengths (e.g. Vandaele et al., 2009), the optical density measured with Filter A also increases. Because the influence of $\mathrm{SO}_{2}$ on the optical density of Filter B is negligible (also for nonperpendicular illumination), the AA increases considerably for off-centred illumination. As the mean illumination angles at the edges of the detector are larger than at the centre of the image, the AA increases towards the sides of the image. The transmission curve thus changes over the range of the detector, depending on the filters chosen and the optical set-up, and every camera has to be carefully characterised (more detailed information on the effect of the filter illumination angle and the influence of different optical set-ups can be found in Kern et al., 2010b). The non-uniformity of the response can be eliminated by proper calibration.

\subsection{Reflections on the interference filters and gas cells}

Radiation arriving at the interference filter is only partly transmitted, even at the peak transmission wavelength. A small fraction is absorbed and a remaining, significant fraction is reflected. If the reflected radiation passes the aperture, part of it is reflected a second time on the windows of the calibration cell. Radiation reflected on the front window of the cell passes the inside of the calibration cell, and therefore the $\mathrm{SO}_{2}$ concentration, two additional times before part of it reaches the detector (see Fig. 2). Since the reflectivity of the two interference filters is different, the reflection effects do not cancel out in the calculation of the AA for a calibration cell image. Without reflection from the interference filter, radiation arriving at the interference filter (with a calibration cell in the light path) can be described by the following:

$I(\lambda)=I_{0} \cdot e^{-\sigma(\lambda) \cdot S} \cdot\left(1-R_{Q}(\lambda)\right)^{4}$,

with the incoming solar radiation $I_{0}$, the $\mathrm{SO}_{2}$ cross-section $\sigma(\lambda)$, the $\mathrm{SO}_{2} \mathrm{CD} S$ along the light path and the Fresnel reflectivity $R_{Q}$ at each quartz window of the calibration cell. The exponent of 4 results from the four transitions between quartz glass and air that influence radiation when passing through the calibration cell. Neglecting higher orders reflection terms, i.e. using only radiation that was reflected once at the interference filter and reflected once at one of the different walls of the calibration cell into the direction of the

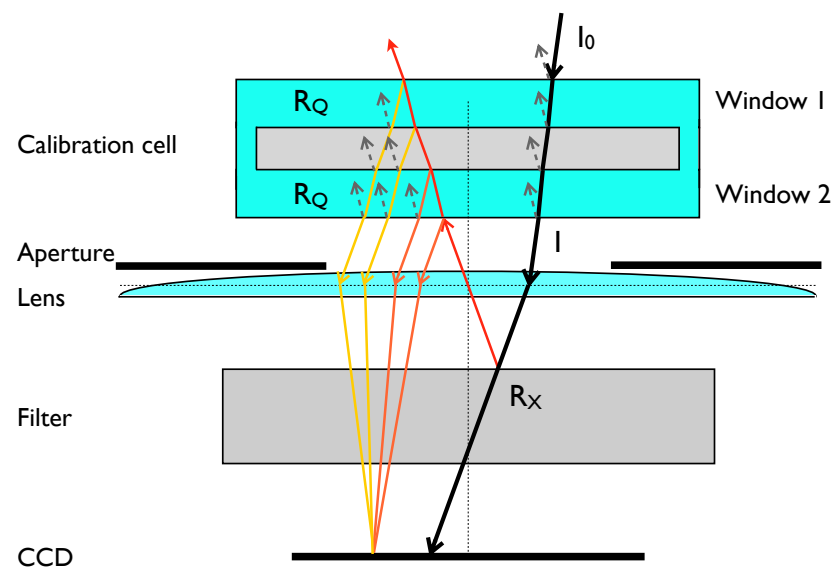

Fig. 2. Sketch of the optical set-up of the $\mathrm{SO}_{2}$ camera (with a calibration cell in place). Reflections on the windows of the calibration cells, which are discussed in Sect. 4.4, are shown. Only part of the radiation arriving at the interference filter is transmitted (black line); radiation reflected from the interference filter (red) is - in turn - partially reflected on Window 1 (yellow) and Window 2 (orange) of the calibration cell. This radiation (some of which has passed the calibration cell three times) reaches the detector and leads to changes in the AA when arriving at the CCD. The grey dashed lines indicate additional reflections that are only accounted for as losses in the calculation of the reflections. Note: reflections can also occur on the lens, but are neglected here since the reflectivity is greatly reduced by an anti-reflective coating.

detector, and also neglecting the angle dependence of $R_{Q}$, we obtain an additional intensity:

$$
\begin{aligned}
\Delta I_{X}(\lambda) & =I(\lambda) \cdot R_{X}(\lambda) \cdot R_{Q} \cdot\left(\sum_{n=1,2}\left(1-R_{Q}\right)^{2 \cdot(n-1)}\right. \\
& \left.+\sum_{n=3,4} e^{-2 \cdot \sigma(\lambda) \cdot S} \cdot\left(1-R_{Q}\right)^{2 \cdot(n-1)}\right) .
\end{aligned}
$$

In this equation $R_{X}=1-T_{X}$ is the reflectivity of the interference filter and $T_{X}$ is the transmittance. The terms for $n=1,2$ describe reflections on Window 2 in Fig. 2; the terms $n=3,4$ describe reflection on Window 1 . Radiation that is reflected from Window 1 has to pass the inside of the calibration cell twice, and is influenced by $\mathrm{SO}_{2}$ absorption. The term $\left(1-R_{Q}\right)^{2 \cdot(n-1)}$ describes the losses at each quartz glass - air interface. For example, radiation that was reflected from the interference filter passes three interfaces before it is reflected on the outer surface of Window 1 and it passes three additional interfaces before arriving at the interference filter again. Thus, losses for the 6 transitions are accounted for by the term $\left(1-R_{Q}\right)^{6}$. Note that reflection on the lens has been neglected because its anti-reflection coating suppresses reflectivity well below that of the calibration cell windows.

A sample calculation for the central wavelengths of the interference filters will give an estimate of the magnitude of 
these effects. The central wavelength of Filter A is $315 \mathrm{~nm}$ with a transmission of $T_{\mathrm{A}, 315 \mathrm{~nm}}=0.64$; the central wavelength of Filter B is $330 \mathrm{~nm}$ with $T_{\mathrm{B}, 330 \mathrm{~nm}}=0.45$ (both measured in the laboratory). Quartz glass, as used for calibration cells, has a refractive index of $n=1.4841$ at $315 \mathrm{~nm}$ and $n=1.4808$ at $330 \mathrm{~nm}$ (Interpolated from Heraeus Datasheet, 2011).

The Fresnel equations generally describe the reflection and refraction of radiation at the interface between two different media with refractive indices $n_{1}$ and $n_{2}$. The reflection coefficients for the polarization plane perpendicular to $\left(R_{\perp}\right)$ and parallel to $\left(R_{\|}\right)$the plane of incidence are given by

$R_{\perp}=\left(\frac{n_{1} \cos \alpha-n_{2} \cos \beta}{n_{1} \cos \alpha+n_{2} \cos \beta}\right)^{2}$
$R_{\|}=\left(\frac{n_{2} \cos \alpha-n_{1} \cos \beta}{n_{2} \cos \alpha+n_{1} \cos \beta}\right)^{2}$.

Here $\alpha$ is the incidence angle and $\beta$ is the refraction angle. For perpendicular $(\alpha=0)$ illumination of the interface between air $(n \approx 1)$ and fused silica with unpolarized radiation, the equations can be simplified to the following:

$R=\frac{R_{\perp}+R_{\|}}{2}=\left(\frac{n-1}{n+1}\right)^{2}$.

We therefore obtain reflection coefficients of $R_{\mathrm{A}}=3.81 \times$ $10^{-2}(315 \mathrm{~nm})$ and $R_{\mathrm{B}}=3.76 \times 10^{-2}(330 \mathrm{~nm})$, respectively, for perpendicular illumination of the calibration cell. These reflection coefficients inserted in Eqs. (3) and (5) lead to $\tau_{\mathrm{A}}=-0.0478, \tau_{\mathrm{B}}=-0.0714$ and thus to an AA of -0.0236 (corresponding roughly to an $\mathrm{SO}_{2}$ $\mathrm{CD}$ of $\approx 2.4 \times 10^{17}$ molec $\mathrm{cm}^{-2}$ ) for an empty calibration cell $\left(S=0\right.$, and assuming $I_{X, \mathrm{M}}(\lambda)=I_{X}(\lambda)+\Delta I_{X}(\lambda)$ ). This means that the AA of a low concentration gas cell recorded at the centre of the image could be significantly skewed (by up to the equivalent of $\sim 100$ ppmm) towards lower values.

In reality the situation is slightly more complex. For one, we do not solely have perpendicular reflection. This leads to an increase in reflectivity (Eqs. 6 and 7). However, most rays that are reflected by the band-pass filter will be blocked by the aperture and will not arrive at the calibration cell again. Of those rays that arrive, only the ones that arrive at the interference filter perpendicular will be reflected to the same position on the detector. In general, each ray will be reflected to another position on the detector. Another effect leading to a smaller influence of the reflection is that the reflectivity of the interference filter in general is somewhat less than $R_{X}=\left(1-T_{x}\right)$ as a fraction of radiation is absorbed inside the interference filter. The magnitude of the described effect strongly depends on the optical set-up but it will also occur for interference filters that are mounted in front of the lens and any calibration cells that are mounted reasonably parallel to the lens.

\subsection{Aerosol influence on the calibration curve}

$\mathrm{SO}_{2}$ cameras that use a second filter to correct for plume condensation and aerosols in the volcanic plume usually assume that these effects are independent of wavelength in the region between 300-335 nm. However, both Mie scattering and Rayleigh scattering show a wavelength dependency.

Mie scattering describes the scattering of radiation on particles that have a size comparable to its wavelength. Mie theory is generally complex, but the cross-section for a given wavelength can be estimated as the following:

$\sigma_{\text {Mie }}(\lambda)=\sigma_{0} \cdot \lambda^{-\alpha}$,

where $\alpha$ is the Ångström exponent (Ångström, 1929, 1961). The Ångström exponent is inversely related to the size of the aerosol particles. For example, values between 0.13 and 2.42 have been found in quiescent degassing volcanic plumes at Mt. Etna (Spinetti and Buongiorno, 2007).

The ratio $\kappa_{\text {Mie }}$ between the scattering cross-sections $\sigma_{\text {Mie }}$ at two different wavelengths $\lambda$ is then

$\kappa_{\mathrm{Mie}}=\frac{\sigma_{\mathrm{Mie}, \lambda_{1}}}{\sigma_{\mathrm{Mie}, \lambda_{2}}}=\left(\frac{\lambda_{1}}{\lambda_{2}}\right)^{-\alpha}$.

For Rayleigh scattering (scattering on molecules and particles with a small size compared to the incident wavelength), the ratio $\kappa_{\text {Ray }}$ between the scattering cross-sections $\sigma_{\text {Ray }}$ at two different wavelengths $\lambda$ is given by

$\kappa_{\text {Ray }}=\frac{\sigma_{\text {Ray }, \lambda_{1}}}{\sigma_{\text {Ray }, \lambda_{2}}}=\left(\frac{\lambda_{1}}{\lambda_{2}}\right)^{-4}$.

The effect of radiation being absorbed or scattered out of the camera's FOV on aerosols as it passes through the volcanic plume is wavelength dependent. With Eq. (10) we get the relationship between the aerosol optical depths $\tau_{\mathrm{A} \text {,aerosol }}$ and $\tau_{\mathrm{B}, \text { aerosol }}$ at two wavelengths:

$\tau_{\mathrm{A} \text {,aerosol }}=\tau_{\mathrm{B}, \text { aerosol }} \cdot \kappa_{\mathrm{Mie}}$.

The influence on $\mathrm{SO}_{2}$ camera measurements can be approximated by inserting the central wavelengths of the interference filters used during the experiments $\left(\lambda_{1}=315 \mathrm{~nm}\right.$ and $\lambda_{2}=330 \mathrm{~nm}$ ) into Eq. (12). An Ångström Exponent of 1.2 was chosen as this value is thought to be representative of a typical volcanic plume (Spinetti and Buongiorno, 2007):

$\tau_{\mathrm{A} \text {,aerosol }}=\kappa_{\mathrm{Mie}} \cdot \tau_{\mathrm{B} \text {,aerosol }}=1.057 \cdot \tau_{\mathrm{B} \text {,aerosol }}$.

This indicates that $\tau_{\mathrm{A} \text {,aerosol }}$ would be $5.7 \%$ higher than $\tau_{\mathrm{B}, \text { aerosol }}$ for a given aerosol optical density. This means that while Filter B does certainly reduce the influence of aerosol on $\mathrm{SO}_{2}$ camera measurements, it does not completely remove it.

For a constant aerosol optical density (AOD) in the volcanic plume, the calibration curve would be shifted towards 
higher AA values. However, it is likely that the AOD increases with increasing $\mathrm{SO}_{2} \mathrm{CD}$. For a linear relationship between $\mathrm{SO}_{2}$ and $\mathrm{AOD}$, we obtain a calibration curve with a lower slope (see Fig. 3).

Besides absorption or scattering radiation out of the camera's FOV, volcanic (as well as atmospheric) aerosols also scatter radiation not originating from behind the plume into the camera's FOV. The AA therefore changes, depending on the amount of radiation scattered into the FOV. We will here focus on scattering of radiation by volcanic aerosol. For the sample calculation we assume that the radiation scattered into the camera's FOV from aerosol is proportional to $I_{\mathrm{A} / \mathrm{B}, \mathrm{M}}$. Geometrical considerations show that the mean light path length for radiation that was scattered into the camera's FOV from inside the volcanic plume is close to the length of a straight line through the plume, assuming a round plume cross-section. The fraction $\delta$ of the measurement intensity $I_{\mathrm{B}, \mathrm{M}}$ at $330 \mathrm{~nm}$ is scattered into the camera FOV. The additional intensity therefore is $\delta \cdot I_{\mathrm{B}, \mathrm{M}}$ for Filter B. For Filter A the fraction of additional radiation is different. We have to take into account that Mie scattering on particles in the plume has different wavelength dependency compared to Rayleigh scattering in the background. This is done by multiplying $\frac{\kappa_{\text {Mie }}}{\kappa_{\text {Rayleigh }}}$. The fraction of additional radiation for Filter $A$ is then $\delta \cdot \frac{\kappa_{\text {Mie }}}{\kappa_{\text {Rayleigh }}}$.

$$
\begin{aligned}
\tau & =\tau_{\mathrm{A}}-\tau_{\mathrm{B}}=-\ln \left(\frac{I_{\mathrm{A}, \mathrm{M}} \cdot\left(1+\delta \cdot \frac{\kappa_{\text {Mie }}}{\kappa_{\text {Rayleigh }}}\right)}{I_{\mathrm{A}, 0}}\right) \\
& +\ln \left(\frac{I_{\mathrm{B}, \mathrm{M}} \cdot(1+\delta)}{I_{\mathrm{B}, 0}}\right)=\tau_{\mathrm{SO}_{2}}+\underbrace{\ln \left(\frac{1+\delta}{1+\delta \cdot \frac{\kappa_{\text {Mie }}}{\kappa_{\text {Rayleigh }}}}\right)}_{\Delta \tau} .
\end{aligned}
$$

Since $\frac{\kappa_{\text {Mie }}}{\kappa_{\text {Rayleigh }}}$ is less than one, there is a shift of the calibration curve towards higher AA values if radiation is scattered into the FOV by Mie scattering (note: the DOAS technique is not affected by this since broad band structures are removed in the DOAS evaluation). For an Ångström exponent of 1.2 and $\delta=0.2$ we obtain $\Delta \tau=0.0206$, with the central wavelengths of the filters used during this work. This means one can obtain a signal equivalent to an $\mathrm{SO}_{2} \mathrm{CD}$ of $2.5 \times 10^{17}$ molec $\mathrm{cm}^{-2}$ or $100 \mathrm{ppmm}$ if $20 \%$ of the measured radiation intensity is scattered into the camera's FOV on aerosol in the volcanic plume.

\section{Data acquisition and evaluation}

\section{$5.1 \mathrm{SO}_{2}$ camera}

The $\mathrm{SO}_{2}$ camera acquired images with both filters sequentially: exposure times were adjusted to keep the maximum measured intensity signal at about $85 \%$ of the maximum intensity ( 65536 counts with the 16 bit ADC). Before and after each measurement period, the camera was pointed towards a region of the sky free of clouds and volcanic gas (if available) to obtain background images for both filters. Normalization with the background images removes vignetting from the camera images, as this effect occurs both in the background as well as in the measurement images. Whenever background images were acquired, images with the calibration cells inserted into the light path and reference spectra for the DOAS evaluation were also recorded.

As a first evaluation step, all camera images were corrected for offset and dark current by subtracting a dark image. Next, the background images $I_{0}$ were scaled such that the average intensity in a gas-free subsection of the plume images $I_{\mathrm{M}}$ match the average intensity in the same subsection of the respective background images. We obtain normalised intensities $I_{\mathrm{A}, 0}^{*}, I_{\mathrm{B}, 0}^{*}$ :

$I_{\mathrm{A}, 0}^{*}=c_{\mathrm{A}} \cdot I_{\mathrm{A}, 0}$

$I_{\mathrm{B}, 0}^{*}=c_{\mathrm{B}} \cdot I_{\mathrm{B}, 0}$

with

$c=\frac{\bar{I}_{\mathrm{M}}^{\text {Clear Sky }}}{\bar{I}_{0}^{\text {Clear Sky }}}$.

The optical density for each filter is then calculated from the plume images $I_{\mathrm{A}, \mathrm{M}}$ and $I_{\mathrm{B}, \mathrm{M}}$, and scaled background images $I_{\mathrm{A}, 0}^{*}$ and $I_{\mathrm{B}, 0}^{*}$ :

$\tau_{\mathrm{A}}=-\ln \frac{I_{\mathrm{A}, \mathrm{M}}}{I_{\mathrm{A}, 0}^{*}}$

$\tau_{\mathrm{B}}=-\ln \frac{I_{\mathrm{B}, \mathrm{M}}}{I_{\mathrm{B}, 0}^{*}}$.

Inserting this in Eq. (3) we obtain the AA:

$\tau=-\ln \frac{I_{\mathrm{A}, \mathrm{M}}}{I_{\mathrm{A}, 0}^{*}}+\ln \frac{I_{\mathrm{B}, \mathrm{M}}}{I_{\mathrm{B}, 0}^{*}}$.

For the comparison with the CD obtained by the I-DOAS and the calculation of the $\mathrm{SO}_{2}$ emission rates, all AA images were corrected for higher sensitivity towards the edges of the detector by dividing each pixel of the AA images by the corresponding pixel of a correction mask (Sect. 4.3). This mask was created by fitting 2 nd order polynomial to the optical densities $\tau_{\mathrm{A}}$ and $\tau_{B}$ from calibration cell images, not considering areas affected by reflections (Sects. 4.4 and 6.2). From these fits a reflection-free AA image of a calibration cell was calculated. The correction mask was then obtained by normalising the AA to 1 in the area were the DOAS telescope is pointing.

\subsection{Spectroscopic retrieval}

The spectra recorded with the two spectrometers (NFOVDOAS, I-DOAS) were evaluated using the DOASIS software package (DOASIS: Kraus, 2006). The standard DOAS retrieval was applied in the wavelength range between 314 and 


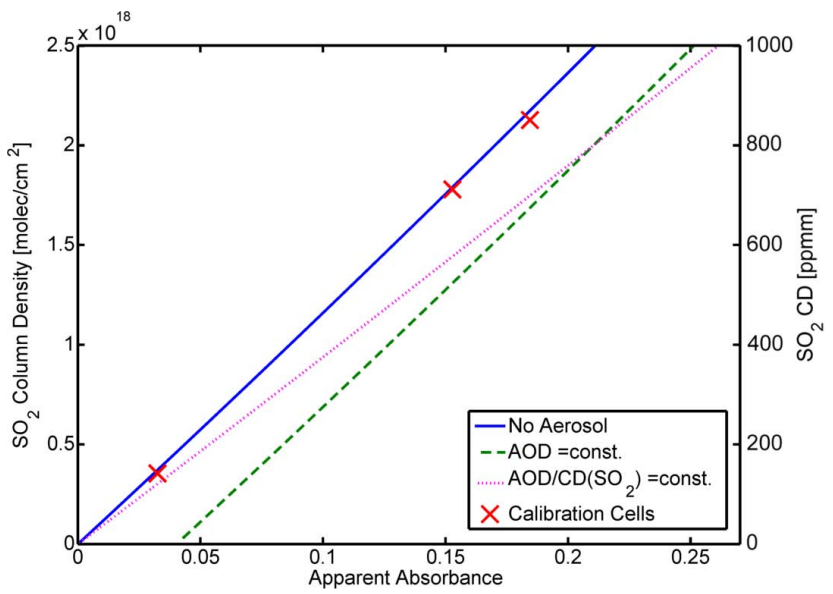

Fig. 3. Camera calibration curves simulated from a sky spectrum recorded with the DOAS spectrometer from Paso de Cortes, Mexico, on 2 March 2011. The calibration curve for the no aerosol case (blue, slope of $1.185 \times 10^{18}$ molec $\mathrm{cm}^{-2}$ or $475 \mathrm{ppmm}$ ) coincides with calibration cell measurements performed at the same time (red crosses). The curve for a constant AOD (shown for $\left.\tau_{\mathrm{B}, \text { Aerosol }}=0.7\right)$ (dashed green line) is parallel to the No Aerosol line, but is shifted by an optical density of 0.04 . Assuming a linear relationship between the $\mathrm{SO}_{2}-\mathrm{CD}$ and $\tau_{\text {Aerosol }}$, as we might expect in a real plume, we obtain the red dotted line. We here assumed $\tau_{\mathrm{B}, \text { Aerosol }}=1.0$ for an $\mathrm{SO}_{2}-\mathrm{CD}$ of $2.0 \times 10^{18}$ molec cm${ }^{-2}$ or $800 \mathrm{ppmm}$. The slope is reduced when compared to the other cases $\left(9.57 \times 10^{18}\right.$ molec $\mathrm{cm}^{-2}$ or $\left.3800 \mathrm{ppmm}\right)$. Details on the simulated camera retrieval can be found in Appendix A.

$326 \mathrm{~nm}$ (e.g. Platt and Stutz, 2008). The absorption crosssections of $\mathrm{SO}_{2}$ (298K, Vandaele et al., 2009) and $\mathrm{O}_{3}$ (both 221 and $241 \mathrm{~K}$, Burrows et al., 1999) were fitted to the measurement spectra along with a Fraunhofer reference spectrum (measured away from the plume in close time proximity) and a Ring spectrum (calculated from the Fraunhofer reference Grainger and Ring, 1962). All cross-sections were convolved to the instrument resolution using the measured instrument response to the $334.15 \mathrm{~nm}$ line of a mercury emission lamp. To correct for small inaccuracies in the pixel-wavelengthmapping, e.g. due to slight changes in the instrument's temperature, the Fraunhofer reference spectrum linked together with the Ring spectrum was allowed to be slightly shifted and squeezed against the measurement spectrum during the DOAS evaluation. All reference cross-sections were also allowed to be shifted and squeezed together as a set. A maximum shift of $\pm 0.2 \mathrm{~nm}$ and squeeze of $\pm 2 \%$ were allowed in both cases.

The DOAS fit for the I-DOAS data was performed individually for each pixel using the same evaluation scheme as for the other spectroscopic data. As the instrument's slit function varies over the detector, the cross-sections were individually convolved for each row of the detector. Due to problems with data logging, no exposure times were available for the I-DOAS. Spectra were therefore only corrected for offset.
However, later measurements determined that the dark current at the same detector temperature can be considered below $0.1 \%$ of the signal for exposures times of approximately $3 \mathrm{~s}$, and is therefore negligible.

\section{Field measurements: set-up and results}

\subsection{The measurement set-up at Popocatépetl}

Measurements from three days (1, 2 and 4 March 2011) will be discussed here. For clarity, these days will be referred to as Day 1, Day 2 and Day 3, respectively, in the rest of the text. Measurements were performed from the ranger's post at Paso de Cortés (longitude: -98.64694, latitude: 19.0867, about $3700 \mathrm{~m}$ above sea level), approximately $7 \mathrm{~km}$ north of the volcano's vent. The viewing direction of the camera and the solar azimuth angle are shown in the top row of Fig. 4 for the start and end times of measurements. The red line indicates the viewing direction used for calibration cell and background image acquisition. Photos giving an impression of the measurement conditions during the three measurement days are shown in the bottom row of Fig. 4. During all measurements, background images and calibration cell images were acquired before and after measurements if an area of clear sky was available. All calibration cell measurements presented here were performed in the morning hours (between 09:30 and 11:00 LT - local time) with approximately the same viewing direction. Additional car traverses were performed with a zenith-looking DOAS instrument to determine the wind-direction. Usually, however, the car traverses were not conducted at the same time as camera measurements.

\subsection{General results from calibration cells}

Figure 5a shows the AA of a calibration cell with an $\mathrm{SO}_{2} \mathrm{CD}$ of $1.8 \times 10^{18}$ molec cm $\mathrm{cm}^{-2}(720 \mathrm{ppmm})$. The image was created by applying Eq. (3) to images taken in the background geometry with the calibration cell covering the entire fieldof-view. As the viewing direction does not change, and the calibration cell measurements are performed within $5 \mathrm{~min}$, no normalisation (Eq. 17) is necessary, i.e. $c_{\mathrm{A}}=c_{\mathrm{B}}=1$. Two features can be seen in Fig. 5a: first, a clear increase in signal with increasing distance from the centre of the image can be observed. We see an increase in AA of up to $85 \%$ between the centre, where AA is lowest, and the corners of the detector, where the AA is highest.

The second feature that can be seen in Fig. 5a is a (slightly off-centre) ring-like structure (arrows) in the middle of the AA image of the calibration cell. This feature can be attributed to reflections on the windows of the calibration cell (Sect. 4.4).

Figure 5b shows an AA image that was created by fitting two-dimensional 2 nd order polynomials to the variation of intensity of the calibration cell optical densities $\tau_{\mathrm{A}}$ and $\tau_{\mathrm{B}}$, without considering the area affected by the reflection 

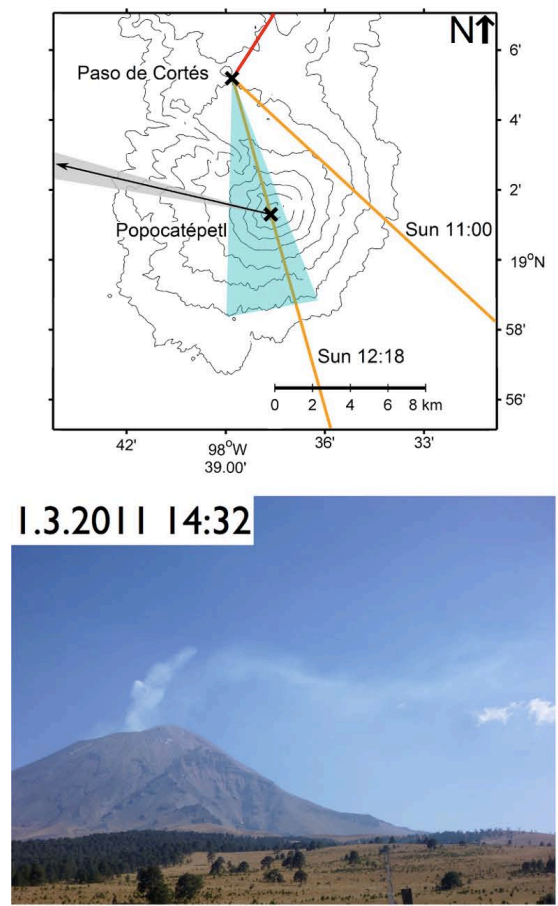

a) I.3.20II
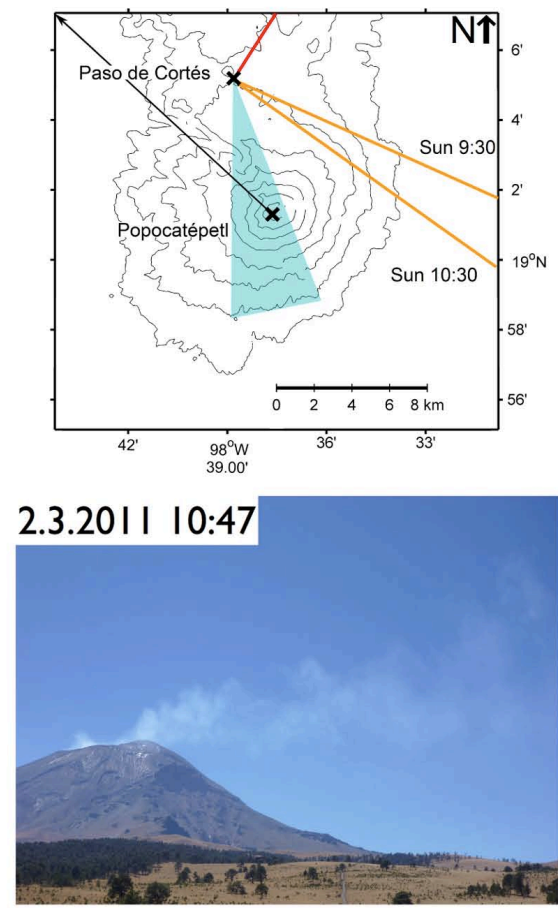

b) $2.3 .201 \mathrm{I}$
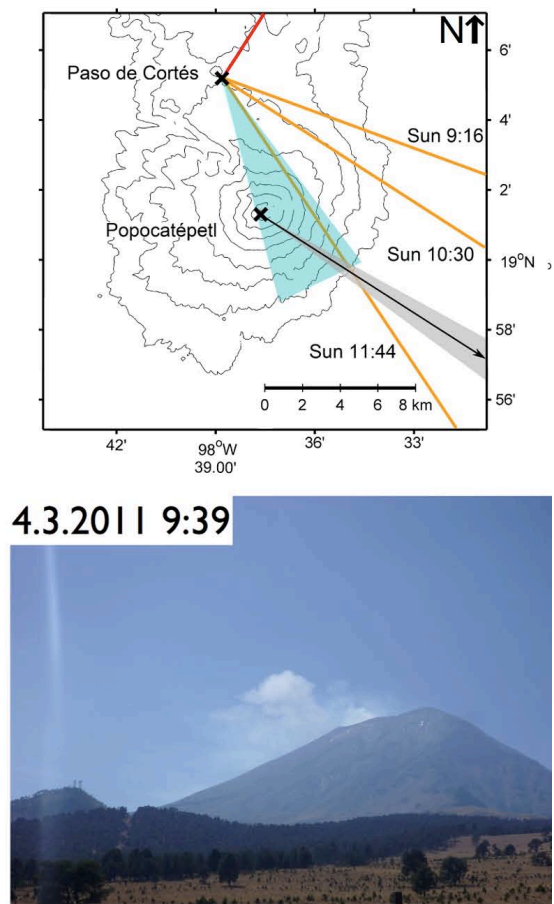

c) $4.3 .201 \mathrm{I}$

Fig. 4. Measurement geometry and photographs of the measurement conditions for the three days discussed in the text: (a) 1 March 2011 , (b) 2 March 2011, (c) 4 March 2011. Top row: sketches of the measurement geometry. For all three measurement days, the solar azimuth during the start and end time of the measurement is shown as orange lines. The camera field-of-view is depicted as a light blue area. The direction in which the calibration cell measurements and background images were made is indicated by the red line. The black arrows show the general wind direction; the grey shaded areas indicate the range of wind directions. Bottom row: pictures of Popocatépetl and plume taken from the instrument position (Paso de Cortés) on all three days. The image from the 1 March 2011 was not taken simultaneously to the measurements, but the measurement conditions were similar.

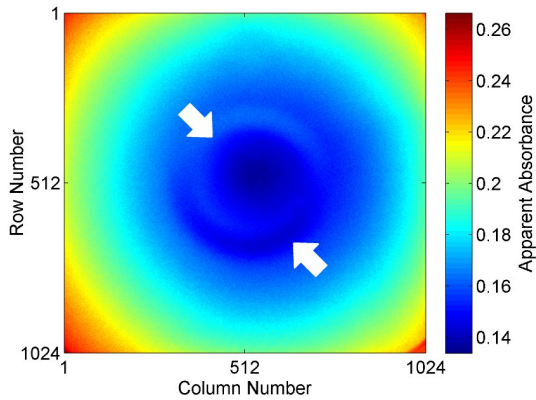

a) Calibration Cell Image

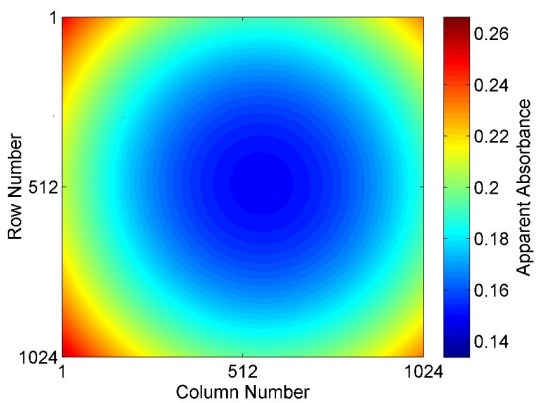

b) Polynomial Fit

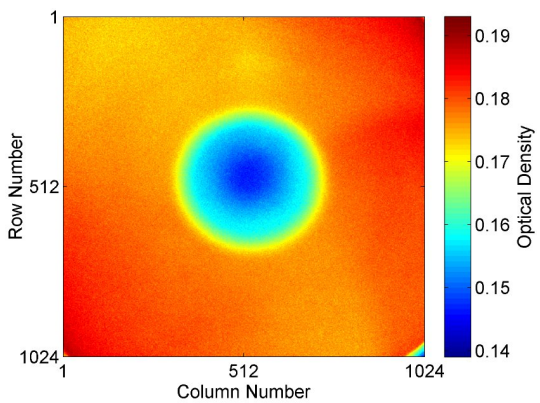

c) Optical Density Filter B

Fig. 5. (a) Colour coded AA-image of a calibration cell with an $\mathrm{SO}_{2} \mathrm{CD}$ of $1.8 \times 10^{18}$ molec cm-2 (720 ppmm). A slight ring-like structure (arrows) is caused by reflections on the calibration cell. (b) AA image that was created from 2nd order polynomial fits to calibration-cell images. The area with reflections in the centre of the images was not considered when determining the best fits. These images were used as a mask to correct for higher sensitivity towards the edges in the I-DOAS comparison and for the $\mathrm{SO}_{2}$ emission rates. (c) Optical density $\tau_{\mathrm{B}}$ image for a calibration cell measurement with Filter B. 


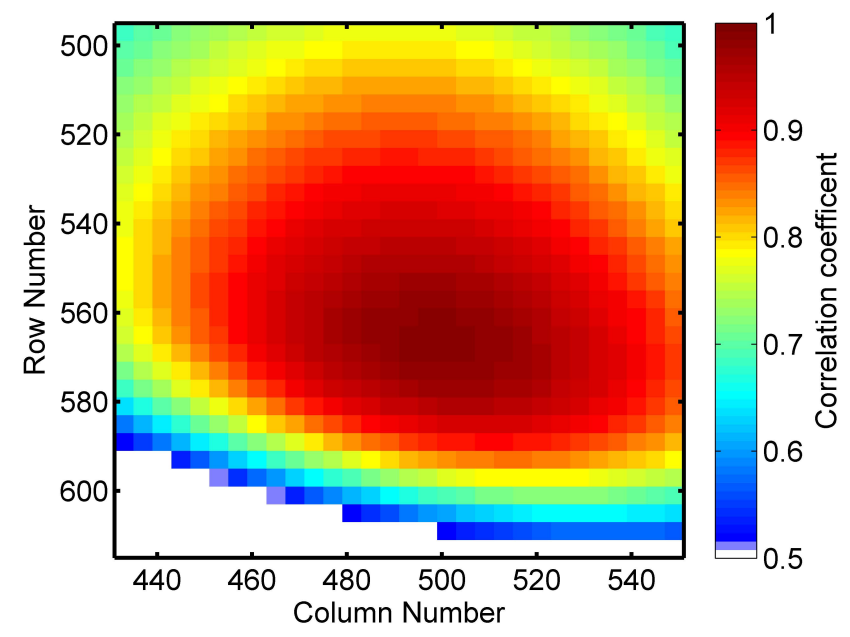

Fig. 6. The viewing direction of the NFOV-DOAS instrument was derived from the correlation coefficient between the $\mathrm{SO}_{2}$ camera AA values and the NFOV-DOAS $\mathrm{SO}_{2}-\mathrm{CDs}$ (see colour scale). The coordinates of highest correlation denote the position of the centre of the DOAS FOV in the camera image (Circle with a radius of 57 pixels). Correlation coefficients of 0.5 or below are shown in white.

features. The residual between the polynomial fit and the calibration cell images was usually below 0.005 (again, only in the area not affected by reflection).

Figure $5 \mathrm{c}$ shows $\tau_{\mathrm{B}}$ from a calibration cell measurement: a circular structure can be observed in the centre of the image, where the optical density is lower, i.e. more radiation arrives in the centre of the detector than at the rest of the detector. As the intensity seen through Filter B is essentially unaffected by $\mathrm{SO}_{2}$ absorption, we would expect a flat signal over the complete detector. However, reflections on the calibration cell windows cause additional radiation to be reflected into the centre of the image (see Fig. 2).

\subsection{Results from the field measurements}

\subsubsection{Calibration}

The FOV of the DOAS instrument within the $\mathrm{SO}_{2}$ camera image had to be derived for the DOAS calibration (see Sect. B). The best correlation between the $\mathrm{SO}_{2} \mathrm{CD}$ timeseries and the AA time-series was found for a circle with a radius of 57 pixels. Small changes in the viewing direction result in small variations of the correlation coefficient (see Fig. 6). Differences in the area with best correlation were found to be very low (on the order of $0.2^{\circ}$ ) between the different days, thus indicating that the pointing of the DOAS telescope in relation to the camera optics had not changed. To assess the uncertainty of the calibration due to the alignment of the instruments FOVs, we investigated the calibration curve for all areas that have a correlation coefficient within $1 \%$ of the maximum correlation coefficient. For these

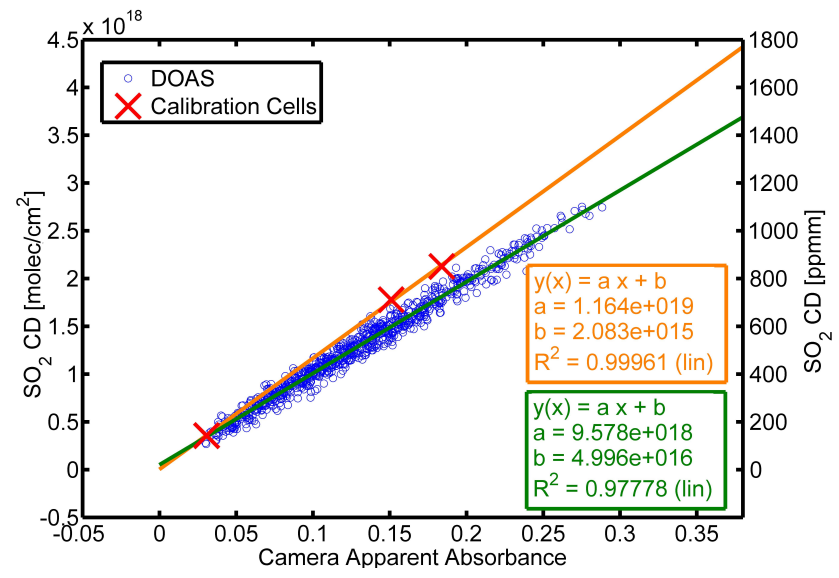

Fig. 7. Calibration curve for the $\mathrm{SO}_{2}$ camera obtained from measurements performed on 1 March 2011 (Day 1). The $\mathrm{SO}_{2}$ column density derived from the DOAS (blue circles) and calibration cells (red crosses) is shown as a function of the AA measured by the camera.

areas we found changes of the slope of the calibration curve of up to $8 \%$ when fitting a first order polynomial to the data (data from Day 3 was not included in these estimates as there was a slight deviation from linear behaviour; see Sect. 6.3.4). Also, the offset for first order calibration polynomials varied between $-2.2 \times 10^{17} \mathrm{molec}^{-2}(\sim-90 \mathrm{ppmm})$ and $1.5 \times 10^{17} \mathrm{molec} \mathrm{cm}^{-2}(60 \mathrm{ppmm})$ across this area. In future measurements, the uncertainty arising from the viewing direction of the DOAS telescope should be reduced by exactly measuring the DOAS FOV at the measurement site.

For calibration with cells we fitted a 2nd order twodimensional polynomial to the optical density images of the calibration cells (the areas with structures from reflections were removed from the fit; see Sect. 5.1). From these 2D-polynomials we created reflection-free AA images. The residual between the 2-D fits and the optical density images were usually below an optical density of 0.005 in the areas without reflection structures, thus leading to an uncertainty of approximately $5 \%$ for the calibration curves. The AA value for the calibration curves was then calculated in the same area as the DOAS FOV in order to be able to compare the two methods. The calibration curves obtained during the three days (see Sects. 6.3.2, 6.3.3 and 6.3.4) differ very little for all of the measurements. The slope of linear fits to the calibration cell $\mathrm{AA} / \mathrm{SO}_{2} \mathrm{CD}$ pairs varied by only about $\sim 1 \%$ during the entire measurement period. This indicates that the instrument was very stable and exhibited a nearly constant sensitivity towards $\mathrm{SO}_{2}$ calibration cells (at close proximity to the instrument).

\subsubsection{Day 1, 1 March 2011}

On this day, the calibration curves from the calibration cells and the DOAS both show a linear relationship between AA 


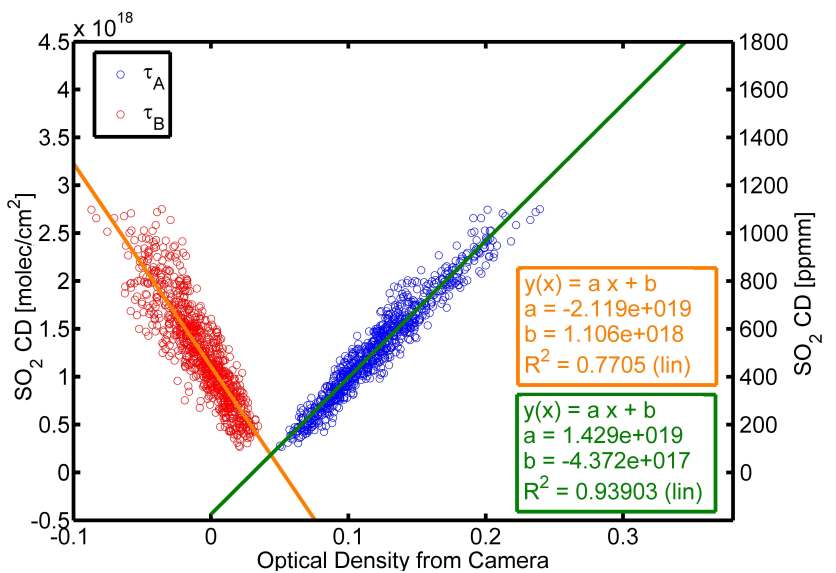

Fig. 8. The $\mathrm{SO}_{2}$ column density from the DOAS plotted against $\tau_{\mathrm{A}}$ and $\tau_{\mathrm{B}}$ for measurements from 1 March 2011 (Day 1). Note the decreasing optical density $\tau_{\mathrm{B}}$ for Filter $\mathrm{B}$ with increasing $\mathrm{SO}_{2}$ column density caused by aerosol scattering in the plume.

and CD (Fig. 7). The DOAS measurements correlate very well with the camera's apparent absorbance time series $\left(R^{2}\right.$ of 0.978 ). However the slopes derived by the two calibration methods differ by almost $20 \%$.

The optical densities $\tau_{\mathrm{A}}$ and $\tau_{\mathrm{B}}$ obtained for the two filters (Fig. 8) each also show a linear dependency on the DOASderived $\mathrm{SO}_{2} \mathrm{CD}$. While $\tau_{\mathrm{A}}$ exhibits the expected increase in magnitude with increasing $\mathrm{SO}_{2}$ load due to absorption, $\tau_{\mathrm{B}}$ actually decreases with increasing $\mathrm{SO}_{2} \mathrm{CD}$. This can be explained by light being scattered toward the instruments on aerosol and cloud droplets that are generally co-located with areas of high $\mathrm{SO}_{2} \mathrm{CD}$. Thus, the plume appears slightly brighter than the background at $330 \mathrm{~nm}$, where $\mathrm{SO}_{2}$ absorption is negligible.

Figure 9 shows the NFOV-DOAS time series in comparison to the $\mathrm{SO}_{2}$ camera time series (average of the AA for all pixels coinciding with the DOAS FOV) from Day 1. After converting the AA to $\mathrm{SO}_{2}$ column densities by multiplying with the calibration factor of $9.58 \times 10^{18}$ molec $\mathrm{cm}^{-2}$ ( $\sim 3800$ ppmm) obtained from the DOAS (see Fig. 7 , the offset was also taken into account), $95 \%$ of the DOAS measurement values lie within $\pm 1.5 \times 10^{17}$ molec cm $^{-2}$ $(\sim 60$ ppmm) of the camera data points.

\subsubsection{Day 2, 2 March 2011}

AA values derived in the DOAS FOV again show very good correlation with the DOAS derived $\mathrm{SO}_{2} \mathrm{CDs}$ on Day 2 (see Fig. 10). This time the calibration curves derived from the DOAS and the calibration cells show good agreement. The slope differs by only about $5.6 \%$, well within the measurement uncertainty, and the offset between the two calibration curves is only $3 \times 10^{16}$ molec $\mathrm{cm}^{-2}(12 \mathrm{ppmm})$. The measurements show that the linear relationship between $\mathrm{AA}$ and $\mathrm{SO}_{2} \mathrm{CD}$ holds true for up to $4 \times 10^{18}$ molec cm $\mathrm{cm}^{-2}$
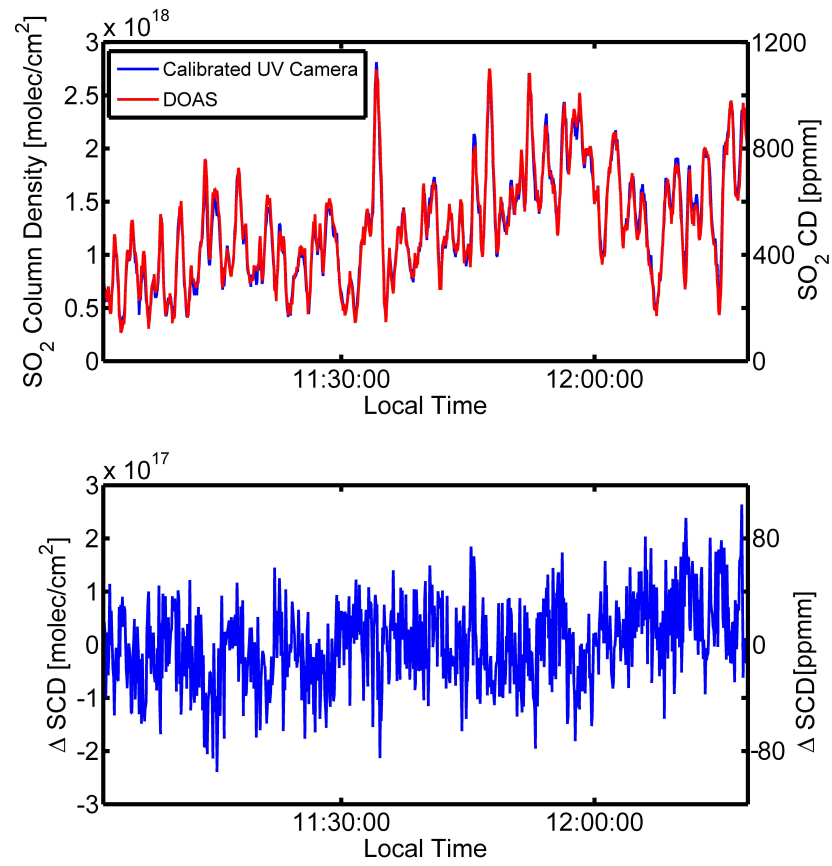

Fig. 9. Top panel: time series of the $\mathrm{SO}_{2}$ camera (average values of all pixels coinciding with the DOAS) and the DOAS from 1 March 2011 (Day 1). $\mathrm{SO}_{2}$ camera values were calibrated with the DOAS. Bottom panel: difference between the calibrated camera and the DOAS system.

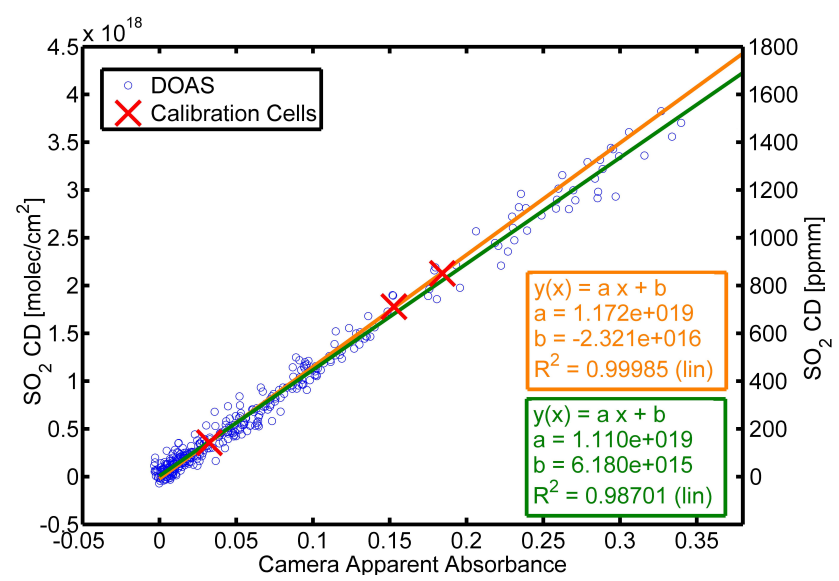

Fig. 10. Calibration curve for the $\mathrm{SO}_{2}$ camera obtained from measurements performed on 2 March 2011 (Day 2).

(approx. 1600 ppmm) in this case. Figure 11 shows the individual optical densities $\tau_{\mathrm{A} / \mathrm{B}}$ for Filter A and Filter B. While the slope for $\tau_{\mathrm{A}}$ is comparable to Day 1, the slope of $\tau_{\mathrm{B}}$ is much steeper than on Day 1, i.e. there is less change of $\tau_{\mathrm{B}}$ with changing $\mathrm{SO}_{2} \mathrm{CD}$, likely indicating a smaller aerosol load in the plume on this day. 


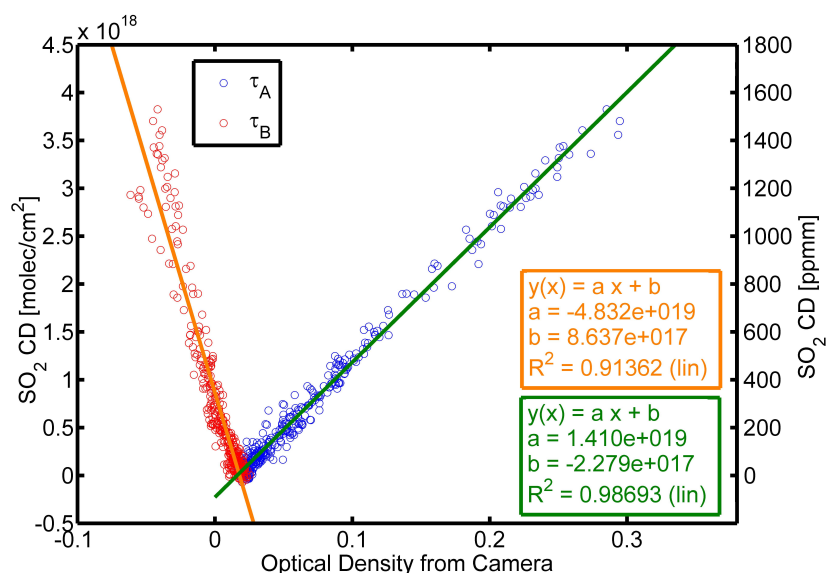

Fig. 11. $\mathrm{SO}_{2}$ column densities from the DOAS plotted against the optical densities for Filter A and Filter B. Measurements from 2 March 2011 (Day 2) at Paso de Cortes.

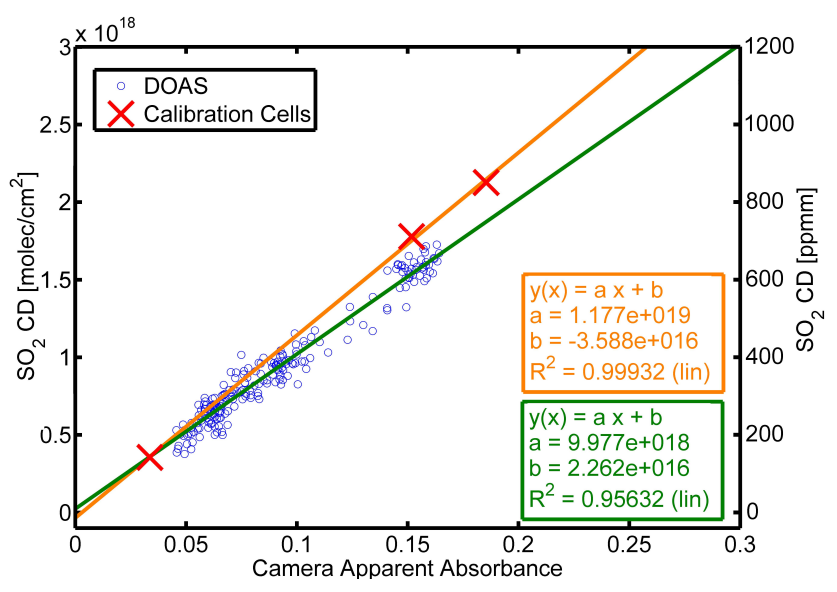

Fig. 12. Calibration curves for the $\mathrm{SO}_{2}$ camera obtained from measurements performed between 09:15 and 09:36 LT on 4 March 2011 (Day 3).

\subsubsection{Day 3, 4 March 2011}

On 4 March 2011 two time-series were recorded, one between 09:15 and 10:00 LT and the other between 10:38 and 11:45 LT. From 09:15 until 09:36 LT, the DOAS calibration curve is similar to Day 1 (Fig. 12). This time interval will hence be referred to as "Part 1". For the rest of the measurements, however, the calibration curve deviates slightly from a linear relationship. For increasing $\mathrm{SO}_{2} \mathrm{CDs}$, all data points are shifted towards higher AA values compared to the calibration cells (Fig. 13). This interval will be referred to as "Part 2". Figure 14 shows both time series. Calibration for this figure was performed with the green NFOV-DOAS curve from earlier in the day (Part 1, Fig. 12). Calibrated in this way, the camera overestimates the $\mathrm{SO}_{2}$ column densities in Part 2 when compared with the DOAS for high $\mathrm{SO}_{2} \mathrm{CDs}$.

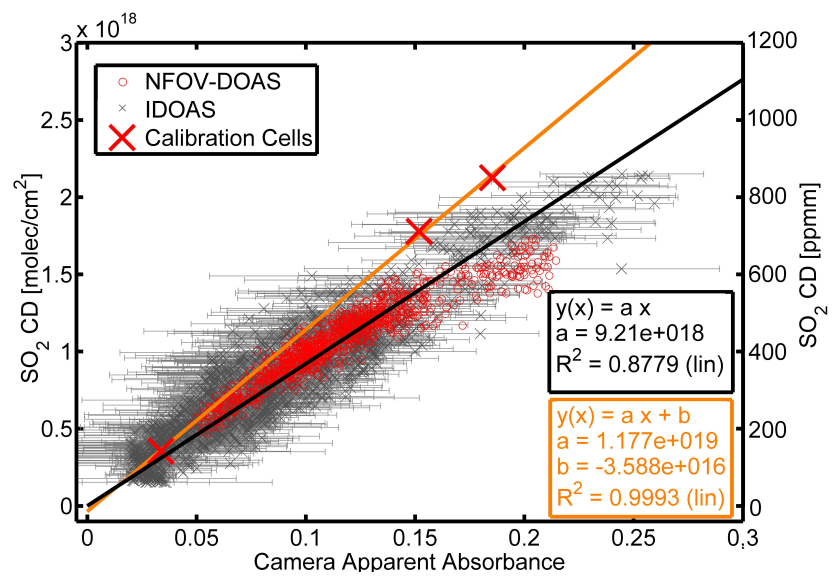

Fig. 13. Calibration lines from the NFOV-DOAS and from an IDOAS compared to the fit curve we obtained from the three calibration cells. For high AA values both DOAS instruments show a deviation from the calibration curve obtained from calibration cell measurements. The black curve is a linear fit to the I-DOAS data that was forced through the origin. The data points from the NFOVDOAS have higher AA values for high $\mathrm{SO}_{2} \mathrm{CDs}$ compared to this fit line.

The $\mathrm{SO}_{2} \mathrm{CDs}$ are plotted as a function of the optical densities for Filter A and B in Fig. 15. The optical densities $\tau_{\mathrm{A}}$ and $\tau_{\mathrm{B}}$ for Part 1 show similar behaviour as on Day 1. For Part 2, most data points are shifted towards higher optical densities.

Simultaneous Imaging DOAS (I-DOAS) measurements (taken between 10:38 and 11:45 LT on Day 3) were used to further investigate the calibration. Comparing the images constructed from the camera images (see Sect. C) and the I-DOAS measurement (Fig. 16), the overall structure of the volcanic plume appears similar in both images. A noteworthy fact is that the camera image seems to have $\mathrm{SO}_{2}$ columns of up to $2 \times 10^{17}$ molec $\mathrm{cm}^{-2}(\sim 80 \mathrm{ppmm})$ in areas where the I-DOAS shows no enhanced $\mathrm{SO}_{2}$. This effect is caused by changes in the background intensity over the field-of-view of the $\mathrm{SO}_{2}$ camera. Due to the sun's azimuthal position (approximately in line with the azimuthal viewing direction of the camera; see Fig. 4), the ratio between the scattered radiation intensity at 315 and $330 \mathrm{~nm}$ is not constant over the entire image.

To further compare the calibrations we reduced the image size to 127 (horizontally) $\times 88$ (vertically) pixels to reduce errors caused by imperfect image alignment. All values that were below a threshold of $1.5 \times 10^{17}$ molec $\mathrm{cm}^{-2}$ $(60 \mathrm{ppmm})$ for I-DOAS measurements and below $0.01 \mathrm{AA}$ for camera images were removed. The remaining data points were used to create a calibration curve that can be compared with the calibration curve obtained from the DOAS instrument incorporated in the camera. The result in Fig. 13 shows that the calibration curve we obtained with the NFOV-DOAS 
Table 2. Average $\mathrm{SO}_{2}$ emission rates for the measurement conducted at Popocatépetl. For all days, mean emission rates are shown for DOAS calibration and cell calibration and with or without correction of the light dilution effect.

\begin{tabular}{|c|c|c|c|}
\hline Measurement time [GMT] & $\begin{array}{l}\text { Day } 1 \\
1 \text { March } \\
\text { 17:01-18:02 }\end{array}$ & $\begin{array}{l}\text { Day } 2 \\
2 \text { March* }^{*} \\
15: 35-16: 10\end{array}$ & $\begin{array}{l}\text { Day } 3 \\
4 \mathrm{March}^{*} \\
15: 16-17: 30\end{array}$ \\
\hline Wind direction $\left[{ }^{\circ}\right]$ & 283 & 313 & $119-125$ \\
\hline Average Wind Speed $\left[\mathrm{m} \mathrm{s}^{-1}\right]$ & 10.2 & 9.4 & 8.0 \\
\hline Maximum $\mathrm{SO}_{2} \mathrm{CD}\left[\right.$ molec $\mathrm{cm}^{-2}$ ] & $3.5 \times 10^{18}$ & $5.6 \times 10^{18}$ & $3.2 \times 10^{18}$ \\
\hline Distance $[\mathrm{km}]$ & 6.8 & 6 & $8-8.5$ \\
\hline DOAS calib. $\mathrm{kg} \mathrm{s}^{-1}$ & 10.56 & 14.34 & 4 \\
\hline Cell calib. $\mathrm{kg} \mathrm{s}^{-1}$ & 12.83 & 15.14 & 5 \\
\hline $\begin{array}{l}\text { Flux Cell calib. } \\
\text { Flux DOAS calib. }\end{array}$ & 1.21 & 1.06 & 1.25 \\
\hline
\end{tabular}

* For 2 March and 4 March the emission rates are only a lower baseline for the emission rate.
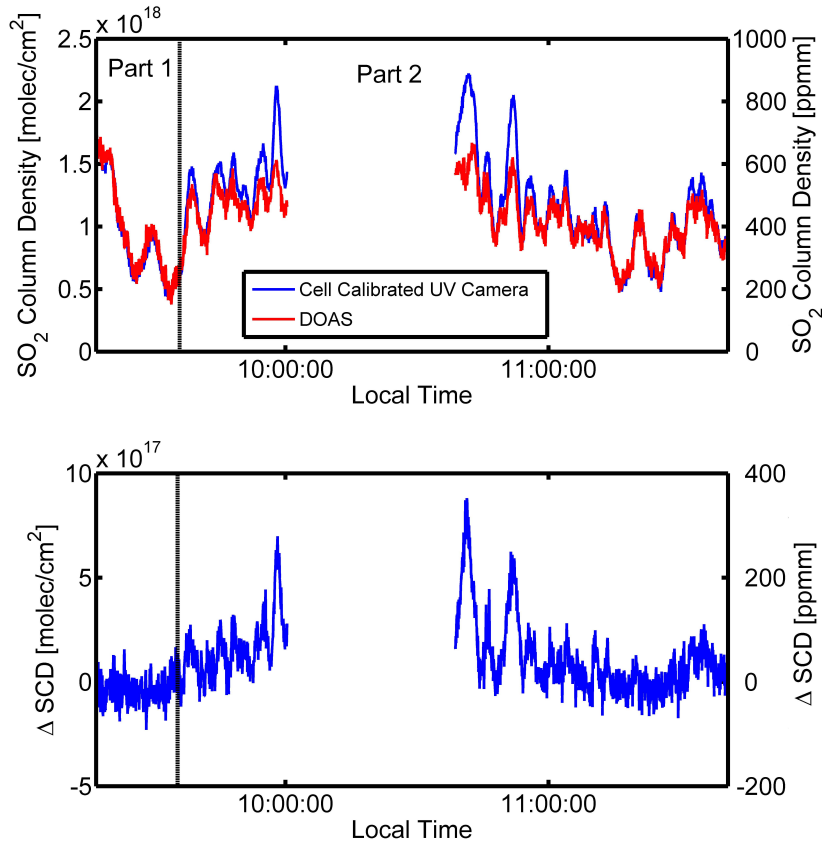

Fig. 14. Top panel: time series from the $\mathrm{SO}_{2}$ camera on 4 March 2011 (calibration constant $9.98 \times 10^{18}$ molec cm $^{-2}$, 4000 ppmm obtained from Part 1) compared to the DOAS measurements. Bottom panel: difference between the camera and the DOAS system. Background images were acquired at 10:05 LT for the first time-series and at 10:36 LT for the second time series.

instrument is in general agreement with the I-DOAS measurements. The calibration obtained from the I-DOAS is slightly more noisy, probably due to an imperfect spatial and temporal alignment. Since the $\mathrm{SO}_{2}$ camera images were spatially transformed to match the I-DOAS FOV and averaged to match the I-DOAS time resolution, small errors due to misalignment are possible. Both calibration curves clearly deviate from the calibration cell measurements for AA values above 0.1 .

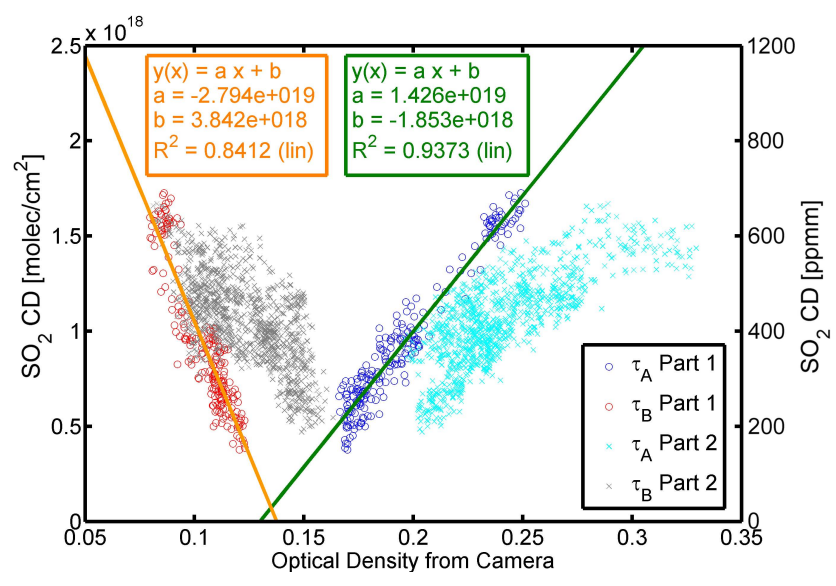

Fig. 15. $\mathrm{SO}_{2}$ column densities from the DOAS measurements plotted against optical densities for Filter A and Filter B for the measurements on Day 3. We see that both optical densities are shifted towards higher values for Part 2.

\subsection{Discussion of calibration results}

On all days the optical density for Filter B decreased with increasing $\mathrm{SO}_{2}$ column density. This shows that more radiation is incident at $330 \mathrm{~nm}$ from areas with high $\mathrm{SO}_{2}$ column densities compared to the background intensity, an indication for radiation being scattered on volcanic aerosol into the camera's FOV. Comparing the optical density $\tau_{\mathrm{B}}$ for Day 1 and 2 (Figs. 8 and 11), one can see that $\tau_{\mathrm{B}}$ has a smaller slope on Day 1 compared to Day 2, possibly due to a higher abundance of volcanic aerosol on Day 1 . However, the measurement geometry shown in Fig. 4 also shows that the relative azimuth between the viewing direction of the camera and the sun's position is smaller on Day 1 compared to Day 2. Since forward scattering is dominant in Mie scattering, a larger fraction of radiation might have been scattered into the camera's FOV by aerosols and condensed water in the plume. As discussed in Sect. 4.5, Mie-scattered radiation leads to an 
increase in AA and therefore to a decrease of the calibration curve. Comparing Figs. 7 and 10 shows that the slope of the calibration curve on Day 1 is indeed lower than on Day 2, as expected for a higher aerosol influence on Day 1.

On Day 3 the situation is more complex. Between 09:15 and 09:36 LT (Part 1), both optical densities $\tau_{\mathrm{A}}$ and $\tau_{\mathrm{B}}$ and the AA behave similar to Day 1, indicating some radiation scattered into the camera's FOV (Figs. 12 and 15).

For Part 2, both optical densities are shifted towards higher values compared to Part 1 (Fig. 15). Less radiation is arriving at the camera's detector for both wavelength channels, which could be caused by more absorbing aerosol in the volcanic plume. $\tau_{\mathrm{B}}$ still shows lower values with increasing $\mathrm{SO}_{2} \mathrm{CDs}$, indicating that besides aerosol absorption some radiation is still scattered into the FOV by volcanic plume aerosol and/or condensed water.

\section{5 $\mathrm{SO}_{2}$ emission rates}

In order to test the influence of the calibration on the retrieved $\mathrm{SO}_{2}$ emission rate, $\mathrm{SO}_{2}$ emission rates for both calibration methods were determined (see Appendix D for details on the emission rate calculation).

On 1 March 2011 we obtained light dilution corrected emission rates ranging between $4 \pm 0.7 \mathrm{~kg} \mathrm{~s}^{-1}$ and $23 \pm 3.9 \mathrm{~kg} \mathrm{~s}^{-1}$, with a mean emission rate of $10.56 \mathrm{~kg} \mathrm{~s}^{-1}$ with the DOAS calibration (see Fig. 17).

On Day 2 and 3 the $\mathrm{SO}_{2}$ emission rates only represent a lower limit, since the plume was partly moving in front and behind Popocatépetl and we could only partly detect the gas emissions. Mean emission rates for all measurement periods with both calibration methods are shown in Table 2. While the $\mathrm{SO}_{2}$ camera calibrated with cells can measure the $\mathrm{SO}_{2}$ emission rate correctly under favourable conditions (only $6 \%$ difference on 2 March 2011), differences in the emission rate of up to $25 \%$ occurred (4 March 2011) when aerosols and condensed water in the volcanic plume significantly influenced the calibration. The difference in the emission rate is significantly lower than the maximum difference of $60 \%$ we found in the calibration curve on Day 3. This is due to the fact that for the emission rate measurements, we have both, high and low $\mathrm{SO}_{2} \mathrm{CDs}$, at lower $\mathrm{SO}_{2} \mathrm{CDs}$ the two calibration methods differ less than $60 \%$ (see Fig. 13).

\section{Conclusions}

In this study we compared different methods for calibrating $\mathrm{SO}_{2}$ camera systems and investigated possible associated errors. While arguably the most straightforward method, calibrating the $\mathrm{SO}_{2}$-sensitivity of UV cameras by placing cells of known concentration in the optical path has some drawbacks. We found that reflections on the calibration cell windows can influence the measured AA and can therefore have a detrimental effect on the calibration. During cell calibration with our instrument, circular structures could be observed in the image centre, a result of multiple reflections on the calibration cell windows. While this effect could potentially be avoided by introducing the cells into the optical path at a nonperpendicular angle, this approach would introduce further complications. The sensitivity of UV cameras is known to vary over the extent of the image (e.g. Kern et al., 2010b), with these variations typically being a function of distance to the image centre. Positioning calibration cells at an angle would introduce an additional component, as the observed cell thickness would then vary across the detector in a nonradial manner. The exact behaviour would depend on the cell placement in or in front of the optical system, but correcting for both effects simultaneously certainly increases complexity and is more prone to errors.

We show that the cell calibration can give misleading results since it cannot account for changes in camera sensitivity due to the presence of aerosol in the plume, as is explained below. Calibration with a co-located DOAS system, on the other hand, worked well. We showed how the correlation between the time series of DOAS column densities and that of the camera's AA values can be used to obtain an accurate estimation of the spectrometer's field-of-view within the camera image. However, in a sensitivity study, the camera calibration was found to be sensitive to the exact size, shape and position of the assumed DOAS FOV. Therefore, accurate characterisation of these parameters is important in obtaining the best possible camera calibration, and any variation in the exact position of the FOV over time should be avoided. Comparison with the imaging DOAS, although slightly more complicated due to the stark difference in image acquisition time (20 min as opposed to $2 \mathrm{~s}$ ), was encouraging and showed that the NFOV-DOAS calibration curve derived in the centre of the image can indeed be used across the entire image as long as the radial variation in camera sensitivity is accounted for.

Besides eliminating the need for manual placement of cells or motorised moving parts in the camera design, integrating a DOAS spectrometer into the camera system also yielded the possibility to assess the influence of volcanic aerosols on the camera calibration. We found that radiation scattered into the camera's field-of-view on aerosols and condensed water in a volcanic plume can lead to a change in the response of the camera towards $\mathrm{SO}_{2}$, since aerosol scattering has a wavelength dependency. Even though no significant change in the camera's calibration between the three discussed days could be determined with the calibration cell method, the DOASderived calibration curves varied significantly. While the difference between cell and DOAS calibration slope was only $6 \%$ under favourable conditions, deviations of up to $60 \%$ were found on 4 March 2011 when a combination of plume aerosol conditions and illumination and viewing geometry led to significant aerosol scattering and absorption effects effects that are not accounted for when calibrating with a gas cell. 
a)

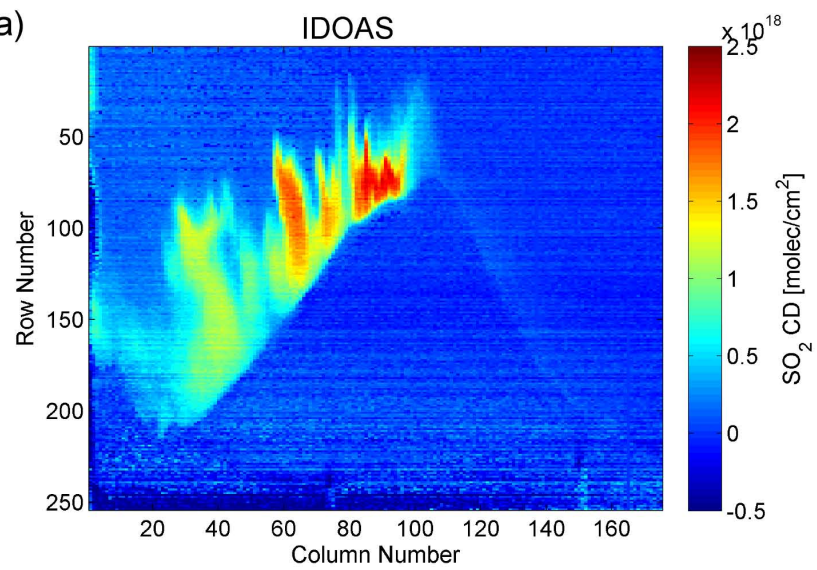

b)

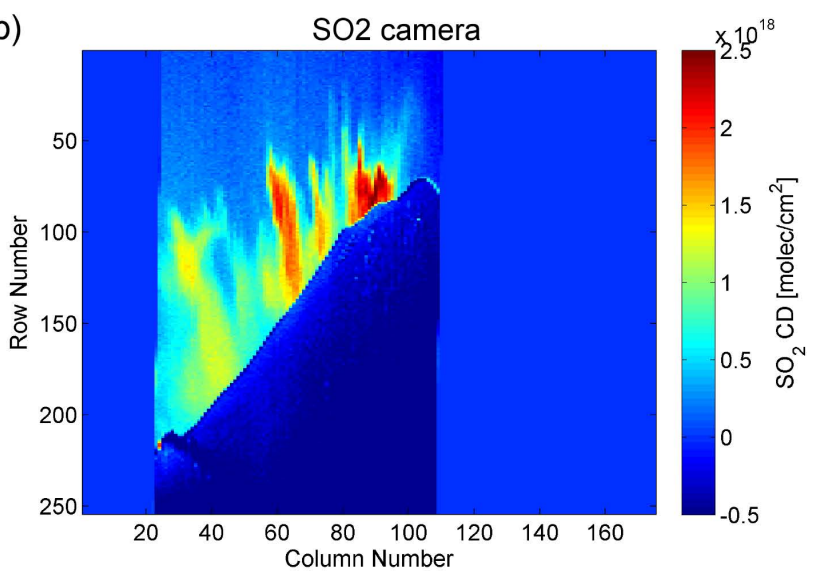

Fig. 16. (a) Image acquired with the I-DOAS on the 4 March 2011 from Paso de Cortes. (b) Image constructed from the $\mathrm{SO}_{2}$ camera measurements to match field-of-view and temporal resolution of the I-DOAS measurements. For this image the camera images were calibrated with the black calibration line obtained from the I-DOAS measurements depicted in Fig. 12.

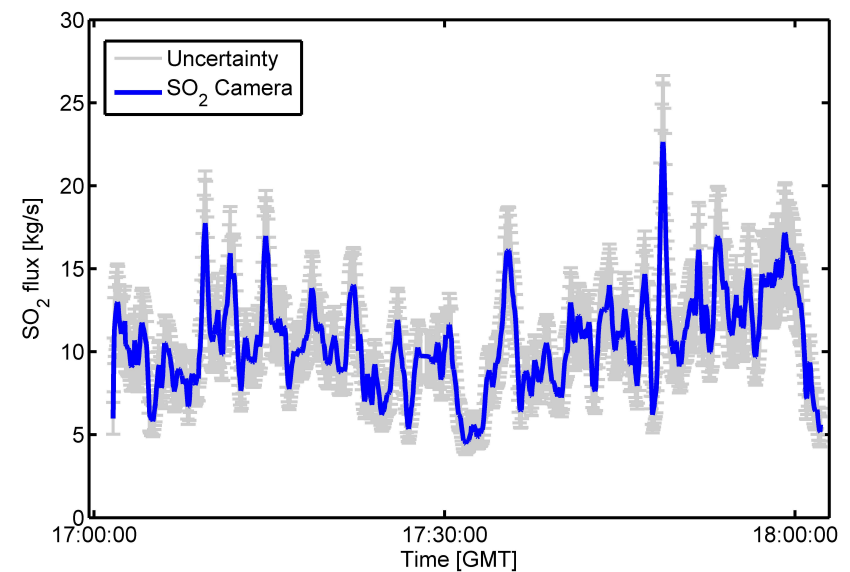

Fig. 17. $\mathrm{SO}_{2}$ emission rate for 1 March 2011. The shown emission rate is light dilution corrected; the shown error consists of the windspeed and the calibration error.

Even in the conditions encountered here, where moderate $\mathrm{SO}_{2}$ column densities (below $\sim 2000 \mathrm{ppmm}$ ) were found and the volcanic plume was generally translucent, the DOASderived calibration will be considerably more accurate than calibrating with cells. It is important to keep in mind, however, that aside from applying an empirical distance correction, the complex radiative transfer of the scene has not been dealt with explicitly. Therefore, this method will also fail in the case of very high $\mathrm{SO}_{2}$ column densities $(\sim$ several thousand ppmm) and visibly opaque plumes. In such conditions, taking complex radiative transfer into account in an explicit manner when evaluating the DOAS data would be necessary (Kern et al., 2012b). In combination with a sophisticated DOAS retrieval technique, the integration of a DOAS spectrometer into the camera instrument would then allow a reasonable estimate of $\mathrm{SO}_{2}$ distributions, even under extreme $\mathrm{SO}_{2}$ conditions and highly opaque plumes.

The difference in the mean emission rate, resulting from the different calibration methods, varied between 6 and $25 \%$ on the different days. After the $\mathrm{SO}_{2}$ camera data was consistently calibrated with the DOAS, a significant variability in the $\mathrm{SO}_{2}$ emission rate was still found. We measured average $\mathrm{SO}_{2}$ emission rates from Popocatépetl Volcano of between 5.7 and $15 \mathrm{~kg} \mathrm{~s}^{-1}$ for the three days of observation. On two of the measurement days, the plume was partly hidden behind the volcano, in this case, even a careful calibration does not allow accurate emission rate measurements. Although the plume was not always in full sight and these values therefore represent conservative estimates, the variability in emission rates was also apparent when the plume was in full view, as was the case on 1 March 2011. On this day alone, emission rates ranged from 4.5 and $23 \mathrm{~kg} \mathrm{~s}^{-1}$, with large variations occurring on time scales of minutes.

This high variability of $\mathrm{SO}_{2}$ emissions at Popocatépetl Volcano is not unique and has in fact been observed at many other volcanoes around the world. Although the processes that cause this variability are not yet well understood, the $\mathrm{SO}_{2}$ camera allows for us to capture these fluctuations at high temporal resolution. It therefore represents a very promising technique for volcano monitoring and systems research. However, we have shown that the accuracy of such UV imaging instrumentation is significantly determined by the ability to obtain an accurate calibration with regard to $\mathrm{SO}_{2}$ sensitivity. For this, the integration of a narrow field-of-view DOAS spectrometer is of immense value. It enables a dynamic calibration under the actual measurement conditions, avoids technical issues associated with placing gas cells into the light path, allows the identification of aerosol scattering effects, and can therefore be considered a key element in the $\mathrm{SO}_{2}$ camera system. 


\section{Appendix A}

\section{Simulation of the AA from a measured solar radiation spectrum}

The AA for a given $\mathrm{SO}_{2}$ column density was simulated and shown in Fig. 3. A solar spectrum $I(\lambda)$ measured at the measurement site with the spectrograph was used in the simulation. Besides the incident radiation, the signal at the detector is also influenced by the transmission curves of the band-pass interference filters $T_{\mathrm{A}}(\lambda), T_{\mathrm{B}}(\lambda)$, the quantum efficiency $Q(\lambda)$ of the detector and by potential $\mathrm{SO}_{2}$ absorption. The extinction due to $\mathrm{SO}_{2}$ absorption is given by the absorption cross-section $\sigma(\lambda)$, the column density $S$. and the Beer-Lambert law of absorption. Therefore, the AA $\tau$ can be simulated using the following equation:

$$
\begin{aligned}
\tau & =-\ln \left(\frac{\sum_{\lambda} I(\lambda) \cdot T_{\mathrm{A}}(\lambda) \cdot Q(\lambda) \cdot \exp (-\sigma(\lambda) \cdot S)}{\sum_{\lambda} I(\lambda) \cdot T_{\mathrm{A}}(\lambda) \cdot Q(\lambda)}\right) \\
& +\ln \left(\frac{\sum_{\lambda} I(\lambda) \cdot T_{\mathrm{B}}(\lambda) \cdot Q(\lambda) \cdot \exp (-\sigma(\lambda) \cdot S)}{\sum_{\lambda} I(\lambda) \cdot T_{\mathrm{B}}(\lambda) \cdot Q(\lambda)}\right)
\end{aligned}
$$

We used the $\mathrm{SO}_{2}$ absorption cross-section $\sigma$ from Vandaele et al. (2009) and estimated the quantum efficiency $Q$ from the Apogee Alta U6 data-sheet. The filter transmission curves $\tau_{\mathrm{A}}$ and $\tau_{\mathrm{B}}$ were measured in the laboratory (the transmission curves for perpendicular illumination were used in the calculations).

\section{Appendix B}

\section{Viewing direction of the DOAS telescope}

It is important to exactly know the area to which the NFOVDOAS telescope is directed because the data from the DOAS together with the corresponding AA data from the $\mathrm{SO}_{2}$ camera are used to create a calibration curve (e.g. Fig. 7). We measured the viewing direction of the telescope relative to the camera by coupling light from a halogen lamp into the spectrometer side of the optical fibre in the laboratory. We then acquired images with the camera to determine the position of the light spot on a wall in the camera image. However, after the measurements were completed, we found that the FOV had changed during the transport to the measurement site or back to the laboratory. Therefore we estimated the size of the FOV and viewing direction of the telescope, relative to the camera FOV, by searching for the best correlation between AA time-series recorded by the $\mathrm{SO}_{2}$ camera and $\mathrm{SO}_{2} \mathrm{CD}$ time series recorded by the NFOV-DOAS, as described in Kern et al. (2010b). We applied this technique with a few minor changes. Instead of quadratic sectors, we chose a round FOV to better approximate the true FOV of the DOAS telescope.

The radius of the FOV was varied and for each radius; the FOV was shifted across the camera image. For each position an AA time series was created by calculating the mean AA value in the FOV as a function of time. As the acquisition time of the spectrograph generally is different from the acquisition time for the camera, the AA time series obtained from the camera images was interpolated to match the acquisition times of the DOAS spectra. After the time interpolation, the linear correlation between the AA time series and the $\mathrm{SO}_{2}$ $\mathrm{CD}$ time series from the DOAS was calculated for each measurement period. This way we obtained the radius with the best correlation, and a "correlation map" that shows where the correlation between the camera's AA time-series and the DOAS's $\mathrm{SO}_{2} \mathrm{CD}$ time-series has its maximum. Although a stable design of the camera-NFOV-DOAS assembly and laboratory calibration are preferable, we recommend checking of the relative alignment by the method described above.

\section{Appendix C}

\section{Comparison between $\mathrm{SO}_{2}$ camera and I-DOAS}

The $\mathrm{SO}_{2}$ camera and the I-DOAS differ in temporal and spatial resolutions. While the $\mathrm{SO}_{2}$ camera acquires an AA image approximately every 3 to $4 \mathrm{~s}$ with a quadratic FOV of roughly $22^{\circ}$ by $22^{\circ}$, the I-DOAS needs between 5 and $25 \mathrm{~s}$ to acquire one column of the image with a FOV of $13^{\circ}$ (vertically) $\times 0.26^{\circ}$ (horizontally). For example, the image that we discuss in this paper was recorded between 10:30 and 11:15 LT on 4 March 2011. It has a spatial extension of $13^{\circ}$ (vertically) $\times 44.5^{\circ}$ (horizontally). The $\mathrm{SO}_{2}$ camera recorded $815 \mathrm{AA}$ images during this time period. The data obtained from the two instruments were carefully prepared to be comparable. As a first step, a transformation matrix was created to translate, rotate, shear and scale the $\mathrm{SO}_{2}$ camera images to the I-DOAS FOV. This was done by manually choosing feature points (e.g. vent of the volcano) that can be distinguished in both the $\mathrm{SO}_{2}$ camera image and in the I-DOAS image. This set of points was used to create the image transformation matrix. After the matrix was applied to all camera images, the images matched a sub-section of the I-DOAS FOV (since the I-DOAS image has a larger horizontally FOV than the $\mathrm{SO}_{2}$ camera). The acquisition start and end time is known for each column of the I-DOAS: for the corresponding image constructed from $\mathrm{SO}_{2}$ camera measurements, we used the average of all camera images recorded between the start and end time to construct the corresponding column for comparison.

The error induced by the image transformation was investigated by comparing several cross-sections through the image in the horizontal and in the vertical direction. From these cross-sections (see Fig. C1) the maximum displacement was 
a)

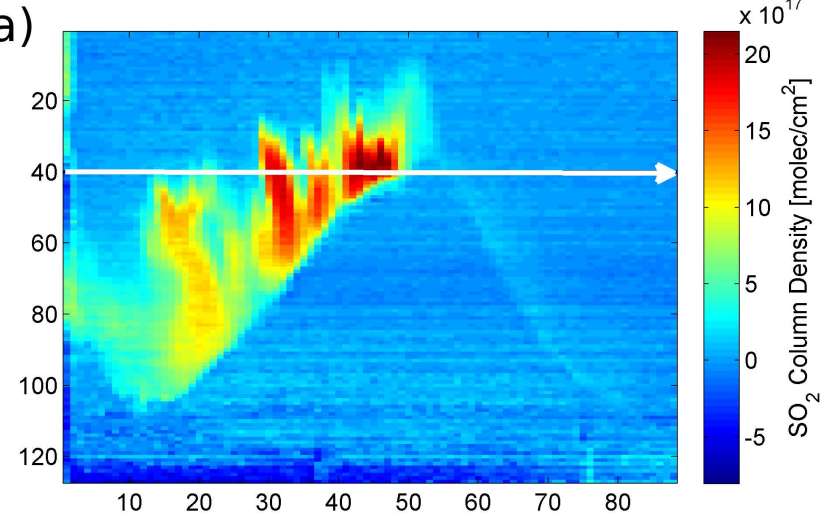

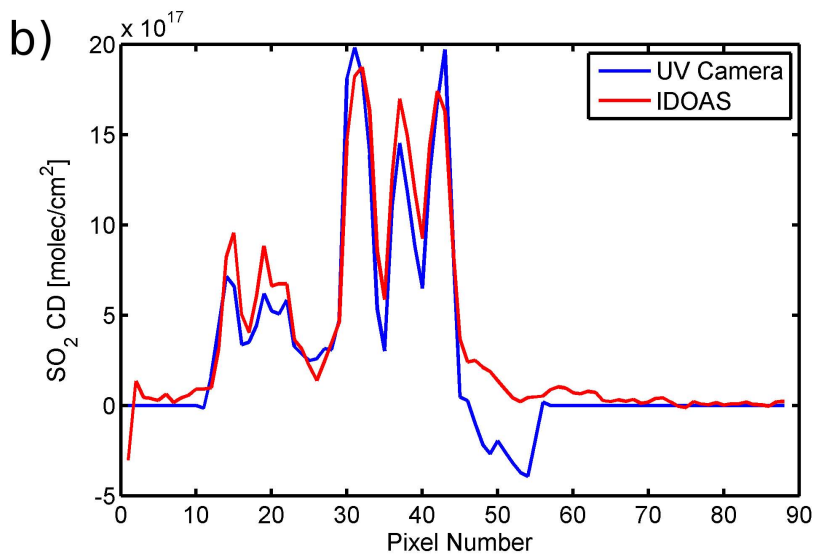

Fig. C1. (a) Reduced resolution I-DOAS image, the white arrow shows the cross-section shown on the right side. (b) Cross-section through the $\mathrm{SO}_{2}$ camera (blue) and the I-DOAS (red) image in row 40.

estimated to be below $\Delta x=1$ pixel in the x-direction, and below $\Delta y=2.5$ pixels in the y-direction. Next, the gradients for the AA image $\frac{\Delta \tau}{\Delta x}$ and $\frac{\Delta \tau}{\Delta y}$ were calculated for each pixel. The uncertainty in $\tau$ originating from the image transformation was calculated using error propagation:

$\Delta \tau=\sqrt{\left(\frac{\Delta \tau}{\Delta x} \cdot \Delta x\right)^{2}+\left(\frac{\Delta \tau}{\Delta y} \cdot \Delta y\right)^{2}}$.

As this error estimation showed that some pixel had rather large errors, we removed all values with an error above $\Delta \tau=0.05$; this, however, did not change the calibration curve.

\section{Appendix D}

\section{$\mathrm{SO}_{2}$ emission rate calculation}

To calculate the $\mathrm{SO}_{2}$ rates, all camera AA values were converted to $\mathrm{SO}_{2}$ column densities. This was done using calibration curves derived from both the DOAS and from the calibration cells (see Figs. 7, 10, 12 and 13).

As measurements were performed at a distance $L$ of $6-$ $8 \mathrm{~km}$ from the volcanic plume, the measured $\mathrm{SO}_{2} \mathrm{CD}$ is influenced by the light dilution effect (Kern et al., 2010a). A correction for this effect as suggested in Bluth et al. (2007) and Vogel et al. (2011) was applied to the column densities $S$ such that:

$S(L)=S_{0} \cdot e^{-\epsilon \cdot \Delta L}$.

$\epsilon$ is an extinction coefficient and depends on the physical state of the atmosphere. We used a value of $\epsilon=0.057 \mathrm{~km}^{-1}$ which was derived by Vogel et al. (2011) for a wavelength of $315.4 \mathrm{~nm}$ for measurements of the plume of Popocatépetl under comparable conditions. However, due to the difference in measurement set-ups between this study and that of Vogel et al. (2011) (especially regarding the altitude of the detector), this extinction coefficient represents a lower boundary for the influence of the light dilution effect. Solving Eq. (D1) for $S_{0}$ therefore yields a conservative estimate of the $\mathrm{SO}_{2} \mathrm{CD}$ in the plume.

Next we summed $\mathrm{SO}_{2}$ CDs up along a cross-section of the plume. The cross-section ideally is perpendicular to the propagation direction of the plume. However, as explained in Mori and Burton (2006) non-perpendicular viewing direction cancels out in the calculation of the emission rate if the wind speed is derived from the camera data (see below), since both the derived wind-speed and the $\mathrm{SO}_{2}$ column density are a function of the viewing direction. In integrating along a plume cross-section we summed up all pixels with column densities exceeding the background noise $(\approx 1-$ $2 \times 10^{17}$ molec cm ${ }^{-2}$ (40-80 ppmm, determined in areas of the pictures not covered by the volcanic plume). This was done for two parallel cross-sections with a difference in azimuth angle of approximately $2^{\circ}$. Cross-correlations of time series of the integrated $\mathrm{SO}_{2}$ column densities were used to determine the time required for $\mathrm{SO}_{2}$ to travel between the two positions (see e.g. McGonigle et al., 2005; Johansson et al., 2009; Boichu et al., 2010). We used a correlation window of roughly $600 \mathrm{~s}$ and obtained a very good correlation between the time-series of the two cross-sections (usually the correlation coefficient was 0.9 or better) with time lags typically between 28 and $35 \mathrm{~s}$.

Wind directions were interpolated from the READY NOAA database (READY, 2012, GDAS data) at an estimated plume altitude of $5500 \mathrm{~m}$. The uncertainty of the modelled wind directions was assessed by comparing wind directions determined by car traverses at a later time of day to modelled wind directions for the same time. Measurements and modelled wind directions differed by on average $10.6^{\circ}$, with a maximum difference of $18^{\circ}$. This greatest deviation was used to find the uncertainty of the distance between the two integrated cross-sections using error propagation. 
The distance between the two cross-sections was calculated from the angle between them and the distance between the instrument and the volcanic plume. The thus obtained wind-speed $v$ represents the wind-speed perpendicular to the viewing direction.

We then calculated the emission rate as:

$\Phi=v \cdot \sum \Delta h_{i} \cdot S_{0}\left(\tau_{i}\right)$

where $\Delta h_{i}$ is the height that one pixel represents at the location of the plume. This was calculated from the distance to the plume and the solid angle covered by one pixel given the camera's object lens.

For a constant calibration factor $c$ the emission rate becomes

$\Phi=v \cdot c \cdot e^{\epsilon \cdot \Delta L} \cdot \sum \Delta h_{i} \cdot \tau_{i}$.

The dominating sources of uncertainty during the measurements were the calibration (uncertainty of $8 \%$ for 1 and 2 March 2011, as explained in Sect. 6.3), and uncertainties in the wind-speed (about $10 \%$, dominated by the uncertainty of the cross-correlation of the time series). Therefore, the total measurement uncertainty of the $\mathrm{SO}_{2}$ emission rate can be estimated as follows:

$\Delta \Phi=\sqrt{\left(\frac{\partial \Phi}{\partial v} \cdot \Delta v\right)^{2}+\left(\frac{\partial \Phi}{\partial c} \cdot \Delta c\right)^{2}}$.

Acknowledgements. We would like to thank Robyn Schofield as editor of the manuscript and the anonymous reviewers, whose comments greatly helped to improve the manuscript. The measurements were performed within the framework of the FIEL-Volcan project and has received funding from CONACYT and the European Community's through FONCICYT [FONCICYT C002-2008-1 ALA 127249] contract no. [93645]. We would like to acknowledge the help of CENAPRED during the realization of the experiments. We would also like to thank the mechanical workshop at the Institute of Environmental Physics in Heidelberg for their great help while building the camera and the I-DOAS set-up. Hugo Delgado Granados thanks the support of DGAPA for sabbatical research. Acknowledgement for the elevation data used in Fig. 4: data available from the US Geological Survey.

The service charges for this open access publication have been covered by the Max Planck Society.

Edited by: R. Schofield

\section{References}

Ångström, A.: On the Atmospheric Transmission of Sun Radiation and on Dust in the Air, Geogr. Ann. A, 11, 156-166, 1929.

Angström, A.: Techniques of Determinig the Turbidity of the Atmosphere, Tellus A, 13, 214-223, 1961.
Bluth, G. J. S., Shannon, J. M., Watson, I. M., Prata, A. J., and Realmuto, V. J.: Development of an ultra-violet digital camera for volcanic $\mathrm{SO}_{2}$ imaging, J. Volcanol. Geoth. Res., 161, 47-56, doi:10.1016/j.jvolgeores.2006.11.004, 2007.

Bobrowski, N., Hönninger, G., Lohberger, F., and Platt, U.: IDOAS: A new monitoring technique to study the $2 \mathrm{D}$ distribution of volcanic gas emissions, J. Volcanol. Geoth. Res., 150, 329-338, doi:10.1016/j.jvolgeores.2005.05.004, 2006.

Boichu, M., Oppenheimer, C., Tsanev, V., and Kyle, P. R.: High temporal resolution $\mathrm{SO}_{2}$ flux measurements at Erebus volcano, Antarctica, J. Volcanol. Geoth. Res., 190, 325-336, doi:10.1016/j.jvolgeores.2009.11.020, 2010.

Burrows, J. P., Richter, A., Dehn, A., Deters, B., Himmelmann, S., Voigt, S., and Orphal, J.: Atmospheric remote-sensing reference data from GOME-2. Temperature-dependent absorption crosssections of $\mathrm{O}_{3}$ in the 231-794 nm range, J. Quant. Spectrosc. Ra., 61, 509-517, 1999.

Dalton, M. P., Watson, I. M., Nadeau, P. A., Werner, C., Morrow, W., and Shannon, J. M.: Assessment of the UV camera sulfur dioxide retrieval for point source plumes, J. Volcanol. Geoth. Res., 188, 358-366, doi:10.1016/j.jvolgeores.2009.09.013, 2009.

Dalton, M. P., Waite, G. P., Watson, I. M., and Nadeau, P. A.: Multiparameter quantification of gas release during weak Strombolian eruptions at Pacaya Volcano, Guatemala, Geophys. Res. Lett., 37, L09303, doi:10.1029/2010GL042617, 2010.

Galle, B., Johansson, M., Rivera, C., Zhang, Y., Kihlman, M., Kern, C., Lehmann, T., Platt, U., Arellano, S., and Hidalgo, S.: Network for Observation of Volcanic and Atmospheric Change (NOVAC): A global network for volcanic gas monitoring: Network layout and instrument description, J. Geophys. Res., 115, D05304, doi:10.1029/2009JD011823, 2010.

Grainger, J. F. and Ring, J.: Anomalous Fraunhofer Line Profiles, Nature, 193, p. 762, doi:10.1038/193762a0, 1962.

Heraeus Spectrosil ${ }^{\circledR} 2000$ Datasheet, HQS-SO Spectrosil: available at: http://optik.heraeus-quarzglas.de/media/webmedia_local/ downloads/Spectrosilsyntheticfusedsilica.pdf (last access: 29 August 2012), May 2012.

Holland, A. S. P., Watson, I. M., Phillips, J.-C., Caricchi, L., and Dalton, M. P.: Degassing processes during lava dome growth: Insights from Santiaguito lava dome, Guatemala, J. Volcanol. Geoth. Res., 202, 153-166, doi:10.1016/j.jvolgeores.2011.02.004, 2011.

Johansson, M., Galle, B., Zhang, Y., Rivera, C., Chen, D., and Wyser, K.: The Dual-Beam mini-DOAS technique - measurements of volcanic gas emission, plume height and plume speed with a single instrument, B. Volcanol., 71, 747-751, doi:10.1007/s00445-008-0260-8, 2009.

Kantzas, E. P., McGonigle, A. J. S., Tamburello, G., Aiuppa, A., and Bryant R. G.: Protocols for UV camera volcanic $\mathrm{SO}_{2}$ measurements, J. Volcanol. Geoth. Res., 194, 55-60, 2010.

Kern, C., Deutschmann, T., Vogel, L., Wöhrbach, M., Wagner, T., and Platt, U.: Radiative transfer corrections for accurate spectroscopic measurements of volcanic gas emissions, B. Volcanol., 72, 233-247, doi:10.1007/s00445-009-0313-7, 2010a.

Kern, C., Kick, F., Lübcke, P., Vogel, L., Wöhrbach, M., and Platt, U.: Theoretical description of functionality, applications, and limitations of $\mathrm{SO}_{2}$ cameras for the remote sensing of volcanic plumes, Atmos. Meas. Tech., 3, 733-749, doi:10.5194/amt-3733-2010, 2010b. 
Kern, C., Werner, C. A., Doukas, M. P., Elias, T., Kelly, P. J., and Sutton, A. J.: Imaging volcanic $\mathrm{SO}_{2}$ plumes with UV cameras, Geophys. Res. Abstr., EGU2012-12596, EGU General Assembly 2012, Vienna, Austria, 2012a.

Kern, C., Deutschmann, T., Werner, C., Sutton, A. J., Elias, T., and Kelly, P. J.: Improving the accuracy of $\mathrm{SO}_{2}$ column densities and emission rates obtained from upward-looking UVspectroscopic measurements of volcanic plumes by taking realistic radiative transfer into account, J. Geophys. Res., 117, 21562202, doi:10.1029/2012JD017936, 2012b.

Kraus, S. G.: DOASIS, A Framework Design for DOAS, Ph.D. thesis, University of Mannheim, 2006.

Lohberger, F., Hönninger, G., and Platt, U.: Ground-Based Imaging Differential Optical Absorption Spectroscopy of Atmospheric Gases, Appl. Optics, 43, 4711-4717, 2004.

Louban, I., Bobrowski, N., Rouwet, D., Inguaggiato, S., and Platt, U.: Imaging DOAS for volcanological applications, B. Volcanol., 71, 753-765, doi:10.1007/s00445-008-0262-6, 2009.

McGonigle, A. J. S., Inguaggiato, S., Aiuppa, A., Hayes, A. R., and Oppenheimer, C.: Accurate measurement of volcanic $\mathrm{SO}_{2}$ flux: Determination of plume transport speed and integrated $\mathrm{SO}_{2}$ concentration with a single device, Geochem. Geophy. Geosy., 6, Q02003, doi:10.1029/2004GC000845, 2005.

McGonigle, A. J. S., Aiuppa, A., Ripepe, M., Kantzas, E. P., and Tamburello, G.: Spectroscopic capture of $1 \mathrm{~Hz}$ volcanic $\mathrm{SO}_{2}$ fluxes and integration with volcano geophysical data, Geophys. Res. Lett., 36, L21309, doi:10.1029/2009GL040494, 2009.

Moffat, A. J. and Millan, M. M.: The applications of optical correlation techniques to the remote sensing of $\mathrm{SO}_{2}$ plumes using sky light, Atmos. Environ., 5, 677-690, 1971.

Mori, T. and Burton, M.: The $\mathrm{SO}_{2}$ camera: A simple, fast and cheap method for ground-based imaging of $\mathrm{SO}_{2}$ in volcanic plumes, Geophys. Res. Lett., 33, L24804, doi:10.1029/2006GL027916, 2006.

Mori, T. and Burton, M.: Quantification of the gas mass emitted during single explosions on Stromboli with the $\mathrm{SO}_{2}$ imaging camera, J. Volcanol. Geoth. Res., 188, 395-400, doi:10.1016/j.jvolgeores.2009.10.005, 2009.
Nadeau, P. A., Palma, J. L., and Waite, G. P.: Linking volcanic tremor, degassing, and eruption dynamics via $\mathrm{SO}_{2}$ imaging, Geophys. Res. Lett., 38, L01304, doi:10.1029/2010GL045820, 2011.

Oppenheimer, C., Francis, P., and Stix, J.: Depletion rates of sulfur dioxide in tropospheric volcanic plumes, Geophys. Res. Lett., 25, 2671-2674, 1998.

Platt, U. and Stutz, J.: Differential Optical Absorption Spectroscopy - Principles and Applications, Physics of Earth and Space Environments, 1st Edn., Springer, Berlin, Heidelberg, New York, 597 pp., 2008.

Real-time Environmental Applications and Display sYstem: Air Resources Laboratory, NOAA, available at: http://ready.arl.noaa. gov/READYcmet.php, last access: May 2012.

Spinetti, C. and Buongiorno, M. F.: Volcanic aerosol optical characteristics of Mt. Etna tropospheric plume retrieved by means of airborne multispectral images, J. Atmos. Sol.-Terr. Phy., 69, 981-994, 2007.

Stoiber, R. E., Malinconico, L. L., and Williams, S. N.: Use of the correlation spectrometer at volcanoes, in: Forecasting volcanic events, edited by: Tazieff, H. and Sabroux, J. C., Elsevier, Amsterdam, 424-444, 1983.

Vandaele, A. C., Hermans, C., and Fally, S.: Fourier transform measurements of SO2 absorption cross sections: II. Temperature dependence in the $29000-44000 \mathrm{~cm}^{-1}(227-345 \mathrm{~nm})$ region, J. Quant. Spectrosc. Ra., 110, 2115-2126, 2009.

Vogel, L., Galle, B., Kern, C., Delgado Granados, H., Conde, V., Norman, P., Arellano, S., Landgren, O., Lübcke, P., Alvarez Nieves, J. M., Cárdenas Gonzáles, L., and Platt, U.: Early inflight detection of $\mathrm{SO}_{2}$ via Differential Optical Absorption Spectroscopy: a feasible aviation safety measure to prevent potential encounters with volcanic plumes, Atmos. Meas. Tech., 4, 17851804, doi:10.5194/amt-4-1785-2011, 2011.

von Glasow, R., Bobrowski, N., and Kern, C.: The effects of volcanic eruptions on atmospheric chemistry, Chem. Geol., 263, 131-142, doi:10.1016/j.chemgeo.2008.08.020, 2009. 